\title{
Article \\ Natural Deep Eutectic Solvent (NADES) Extraction Improves Polyphenol Yield and Antioxidant Activity of Wild Thyme (Thymus serpyllum L.) Extracts
}

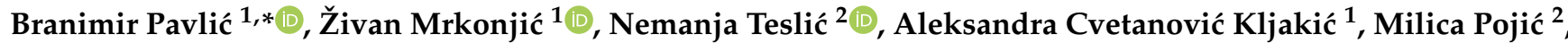 \\ Anamarija Mandić ${ }^{2}$, Alena Stupar ${ }^{2} \mathbb{D}$, Filipa Santos ${ }^{3}$, Ana Rita C. Duarte ${ }^{3}$ and Aleksandra Mišan ${ }^{2, * \mathbb{D}}$ \\ 1 Faculty of Technology, University of Novi Sad, Blvd. cara Lazara 1, 21000 Novi Sad, Serbia; \\ zivan_mrkonjic@hotmail.com (Ž.M.); a.c.istrazivac@gmail.com (A.C.K.) \\ 2 Institute of Food Technology, University of Novi Sad, Blvd. cara Lazara 1, 21000 Novi Sad, Serbia; \\ nemanja.teslic@fins.uns.ac.rs (N.T.); milica.pojic@fins.uns.ac.rs (M.P.); \\ anamarija.mandic@fins.uns.ac.rs (A.M.); alena.tomsik@fins.uns.ac.rs (A.S.) \\ 3 LAQV, REQUIMTE, Departamento de Química, Nova School of Science and Technology, \\ 2829-516 Caparica, Portugal; mfca.santos@campus.fct.unl.pt (F.S.); ard08968@fct.unl.pt (A.R.C.D.) \\ * Correspondence: bpavlic@uns.ac.rs (B.P.); aleksandra.misan@fins.uns.ac.rs (A.M.)
}

Citation: Pavlić, B.; Mrkonjić, Ž.; Teslić, N.; Kljakić, A.C.; Pojić, M.; Mandić, A.; Stupar, A.; Santos, F.; Duarte, A.R.C.; Mišan, A. Natural Deep Eutectic Solvent (NADES) Extraction Improves Polyphenol Yield and Antioxidant Activity of Wild Thyme (Thymus serpyllum L.) Extracts. Molecules 2022, 27, 1508. https://doi.org/10.3390/ molecules27051508

Academic Editor: Alessandra Gentili

Received: 25 January 2022

Accepted: 15 February 2022

Published: 23 February 2022

Publisher's Note: MDPI stays neutral with regard to jurisdictional claims in published maps and institutional affiliations.

Copyright: (C) 2022 by the authors. Licensee MDPI, Basel, Switzerland. This article is an open access article distributed under the terms and conditions of the Creative Commons Attribution (CC BY) license (https:// creativecommons.org/licenses/by/ $4.0 /)$.

\begin{abstract}
Wild thyme (Thymus serpyllum L.) herbal dust has been recognized as a potential underutilized resource for the recovery of antioxidants. The aim of this paper was to optimize natural deep eutectic solvent (NADES) extraction of polyphenols to obtain improved antioxidant activity of extracts determined by selected in vitro assays (DPPH, FRAP, and ABTS). Twenty different NADES systems were investigated in the first step of the screening of the extraction solvent and L-proline (Pro)-glycerine (Gly) based solvents provided the best results. Preliminary experiments organized by $2^{5-1}$ fractional factorial design narrowed down the number of extraction factors from five (temperature, extraction time, NADES type, water content and L/S ratio) to three and determined their experimental domain for the final step. A face-centered central composite design with temperature (40-55-70 $\left.{ }^{\circ} \mathrm{C}\right)$, extraction time (60-120-180 $\mathrm{min}$ ) and L/S ratio (10-20-30 g NADES/g sample) was applied for influence analysis and process optimization. Multi-response optimization suggested a temperature of $65^{\circ} \mathrm{C}$, time of extraction of $180 \mathrm{~min}$ and L/S ratio of $28 \mathrm{~g}$ NADES/g DW as optimal extraction parameters. Experimental validation confirmed good agreement between experimental and predicted results in the extract obtained at optimal conditions and the interactions in the most
\end{abstract} suitable NADES (N16; Pro-Gly- $\mathrm{H}_{2} \mathrm{O} ; 1: 2: 1$ ) were confirmed by the ${ }^{1} \mathrm{H}-\mathrm{NMR}$.

Keywords: Thymus serpyllum L.; NADES; polyphenols; antioxidant activity; RSM optimization

\section{Introduction}

Wild thyme (Thymus serpyllum L.) is an aromatic plant belonging to the Lamiaceae family. This herb is widely used thanks to its biological activities, such as antiseptic, antitussive, analgesic, anthelmintic, diaphoretic, expectorant, spasmolytic, carminative and diuretic activities [1,2]. Traditionally, it has been most frequently used in problems related to digestive, respiratory and urogenital tracts [1]. The reason for all the aforementioned possibilities for use is the high content of polyphenols, which represent compounds of interest in the present research.

Nowadays, a lot of focus is placed on the valorization of industrial waste, using more effective energy and solvents recognized as safe, which is underlined with the main principles of green extraction [3-5]. Furthermore, designing the production line with a minimal number of processing steps and obtaining a safe, non-denatured and biodegradable extract without concomitants as a final product lead to the fact that green extraction processes of natural products present a desirable approach for the isolation of 
antioxidants [3,6]. The most prominent representatives of green extraction techniques are extractions assisted with microwaves, ultrasounds and pulsed electric fields, as well as extractions based on using solvents at sub- and supercritical level and natural deep eutectic solvents (NADES), with the possibility of combining them.

In addition, conventional solid-liquid, ultrasound-assisted (UAE) and pressurized liquid extractions (PLE) have proven to be a great approach for antioxidant recovery from T. serpyllum herbal dust, using ethanol as an extraction solvent $[7,8]$. On the other hand, considering the fact that conventional solvents could be flammable, volatile and toxic, their daily use can become problematic for humans and generally for environmental persistence and/or photochemical ozone creation [9]. There is also a growing incentive to research alternative solvents that would retain the technological properties of organic solvents and at the same time have a favorable impact on human health and the environment. In recent years, the development of alternative solvents has focused on NADES. They have shown the greatest potential in the field of green chemistry, due to the fact that they are abundant, inexpensive, recyclable and attractive for food, cosmetic and pharmaceutical applications [10-12]. So far, many studies have successfully conducted NADES extraction in order to obtain high-quality extracts from various plants, such as from native Greek medicinal plants [10], olive pomace [13], lemon verbena [14], peppermint and lemon balm [15], sour cherry pomace [16] and blueberry [17]. Another great feature of NADES is its potential biological activity, bioavailability and the possibility of an untitled number of solvent combinations for their preparation $[17,18]$. Therefore, NADES extraction represents an innovative technique that has broadened curiosity among scientific circles and has already proven great potential in the field of extraction and isolation of bioactive compounds, as well as their application in various industry branches. Aerial parts of wild thyme (Thymi serpylli herba) were suggested as official preparation of expectorants [19]; therefore, the application of wild thyme extracts obtained by NADES extraction could be considered in expectorant syrup formulations.

The main objective of this study was to valorize T. serpyllum herbal dust as raw material for antioxidant recovery using NADES extraction. The study consisted of three phases, where in the initial one, according to total phenol content (TP) and antioxidant properties of obtained extracts, two of the twenty different NADES systems were selected. The second phase encompassed choosing the most influential parameters and to find their domain, by the evaluation of extraction parameters (temperature, extraction time, liquid-solid (L/S) ratio, NADES type and water content in the solvent) using $2^{5-1}$ fractional factorial design. Finally, the main experiments were performed using response surface methodology (RSM) in order to conduct the optimization of polyphenol recovery from T. serpyllum using desirability function with $\mathrm{Y}, \mathrm{TP}$, total flavonoid content (TF) and antioxidant activity determined toward DPPH, ferric ion reducing antioxidant power (FRAP) and ABTS assays as target responses. Finally, validation was done and the structure and nature of optimized NADES was determined by nuclear magnetic resonance spectroscopy (NMR).

\section{Results and Discussion}

\subsection{Screening of the Extraction Solvent}

Natural deep eutectic solvents (NADES) have been exhaustively applied for the recovery of polyphenols recently, although no application on the recovery of wild thyme (Thymus serpyllum L.) polyphenols has been found in recent literature. Fernandez et al. [20] published an in-depth review of NADES application on the isolation of different compounds from natural resources, among them polyphenols, where it could be observed that a huge variety of NADES could be selected as optimal solvents depending on the physicochemical properties of target molecules and plant material characteristics. Therefore, the screening of the extraction solvent was performed as an initial step in the case study of extraction of wild thyme bioactives. Twenty NADES mixtures, given in Table 1, were prepared for that purpose. All other extraction parameters were held constant in order to obtain information 
about the influence of NADES type using the OFAT approach, while TP and scavenging capacity toward DPPH radicals were measured responses.

Table 1. $2^{5-1}$ fractional factorial design was used for the preliminary study with the experimental domain of the independent factors and observed values of target responses.

\begin{tabular}{|c|c|c|c|c|c|c|c|c|c|c|c|c|}
\hline \multirow{3}{*}{$\begin{array}{c}\text { Run } \\
1\end{array}$} & \multicolumn{10}{|c|}{ Factors } & \multicolumn{2}{|c|}{ Responses } \\
\hline & \multicolumn{2}{|c|}{$\begin{array}{c}\text { A: Temperature } \\
{\left[{ }^{\circ} \mathrm{C}\right]}\end{array}$} & \multicolumn{2}{|c|}{$\begin{array}{c}\text { B: Extraction Time } \\
{[\text { min] }}\end{array}$} & \multicolumn{2}{|c|}{$\begin{array}{c}\text { C: L/S Ratio } \\
\text { [g NADES/g DW] }\end{array}$} & \multicolumn{2}{|c|}{ D: NADES Type * } & \multicolumn{2}{|c|}{$\begin{array}{c}\text { E: Water Content } \\
{[\%]}\end{array}$} & \multirow{2}{*}{$\begin{array}{c}\text { TP } \\
{[\mathrm{mg} \mathrm{GAE} / \mathrm{g}]} \\
57.79\end{array}$} & \multirow{2}{*}{$\begin{array}{c}\begin{array}{c}\text { DPPH } \\
\text { [mg TE/g] }\end{array} \\
74.55\end{array}$} \\
\hline & -1 & 50 & 1 & 120 & 1 & 20 & Level 2 & N16 & -1 & 20 & & \\
\hline 2 & 1 & 60 & -1 & 60 & 1 & 20 & Level 2 & N16 & -1 & 20 & 63.41 & 84.86 \\
\hline 3 & -1 & 50 & 1 & 120 & -1 & 10 & Level 2 & N16 & 1 & 25 & 53.57 & 63.45 \\
\hline 4 & -1 & 50 & 1 & 120 & 1 & 20 & Level 1 & N15 & 1 & 25 & 54.19 & 57.96 \\
\hline 5 & -1 & 50 & -1 & 60 & 1 & 20 & Level 1 & N15 & -1 & 20 & 50.62 & 54.25 \\
\hline 6 & 1 & 60 & -1 & 60 & 1 & 20 & Level 1 & N15 & 1 & 25 & 52.11 & 52.50 \\
\hline 7 & 1 & 60 & 1 & 120 & -1 & 10 & Level 1 & N15 & 1 & 25 & 44.13 & 37.59 \\
\hline 8 & 1 & 60 & 1 & 120 & -1 & 10 & Level 2 & N16 & -1 & 20 & 59.52 & 69.75 \\
\hline 9 & -1 & 50 & -1 & 60 & -1 & 10 & Level 2 & N16 & -1 & 20 & 51.87 & 54.60 \\
\hline 10 & 1 & 60 & 1 & 120 & 1 & 20 & Level 1 & N15 & -1 & 20 & 52.37 & 54.25 \\
\hline 11 & -1 & 50 & -1 & 60 & 1 & 20 & Level 2 & N16 & 1 & 25 & 58.47 & 64.19 \\
\hline 12 & 1 & 60 & 1 & 120 & 1 & 20 & Level 2 & N16 & 1 & 25 & 64.24 & 91.16 \\
\hline 13 & -1 & 50 & -1 & 60 & -1 & 10 & Level 1 & N15 & 1 & 25 & 43.31 & 39.97 \\
\hline 14 & 1 & 60 & -1 & 60 & -1 & 10 & Level 2 & N16 & 1 & 25 & 54.84 & 72.47 \\
\hline 15 & -1 & 50 & 1 & 120 & -1 & 10 & Level 1 & N15 & -1 & 20 & 44.45 & 40.13 \\
\hline 16 & 1 & 60 & -1 & 60 & -1 & 10 & Level 1 & N15 & -1 & 20 & 44.93 & 39.88 \\
\hline
\end{tabular}

* categorical variable.

TP in wild thyme extracts was in the range of 35.33 to $52.43 \mathrm{mg} \mathrm{GAE} / \mathrm{g}$. It could be observed that NADES based on L-proline (N15 and N16) provided the highest TP values (47.61 and $52.43 \mathrm{mg} \mathrm{GAE} / \mathrm{g}$ ) (Figure 1a). N15 was based on L-proline and lactic acid (1:2), while N16 was made of L-proline, glycerine and water (1:2:1). Water was an integral compound in the N16 mixture, which significantly improved TP $(p<0.05)$. The range of results for the scavenging capacity of DPPH radicals was $37.79-78.73 \mathrm{mg}$ TE/g (Figure 1b). Similarly, extracts obtained by N15 and N16 exhibited the highest activity (55.55 and $78.73 \mathrm{mg} \mathrm{TE} / \mathrm{g}$ ), even though no significant difference $(p>0.05)$ was observed between the samples obtained by N15, N9 (ChCl-Gly; 1:2) and N20 (PD-ChCl- $\left.\mathrm{H}_{2} \mathrm{O} ; 1: 1: 1\right)$. Good Pearson's correlation was observed between TP and DPPH data $(r=0.755 ; p<0.05)$, suggesting that polyphenols were the main compounds responsible for antioxidant activities in T. serpyllum extracts.

There are several examples where Pro-Gly-based NADES were the best solvent mixture for the recovery of polyphenolic compounds. This could be explained by the significant affinity of polyphenols for extended proteins and peptides that contain a high proportion of Pro residues in their sequences [21]. According to Nam et al. [22], NADES with Pro-Gly (2:5) was found to be the best solvent for the isolation of flavonoids (quercetin, kaempferol and isorhamnetin glycosides) from flowers of Sophora japonica. L-proline-based NADES mixtures with organic acids were found to be very useful in the isolation of different polyphenol groups. Mansinhos et al. [23] performed screening of 10 NADES systems for the recovery of bioactives from Lavandula pedunculata subsp. lusitanica and observed that the highest TP and antioxidant activities determined by different in vitro assays were obtained by Pro-LA (1:1). Huang et al. [24] performed comprehensive studies focused on the investigation of 25 different NADES mixtures on the isolation of puerarin flavones from the root of Pueraria lobata and observed that the utilization of Pro-MA solvent improves the yield of target compounds, as well as their oral bioavailability.

Despite the enormous potential of NADES solvents, their high viscosity has been recognized as the main disadvantage. Dai et al. [25] reported that the addition of a small amount of water into NADES solvents could reduce their viscosity and increase their conductivity. According to the results from Figure 1, Pro-Gly with a higher content of water also provided significantly higher TP and DPPH. Furthermore, it has been reported that NADES based on proline could improve the solubility and bioavailability of certain flavonoids, such as rutin [26]. Taking all this into consideration, N15 and N16 solvents, both based on Pro-Gly, were selected for further research. 
(a)

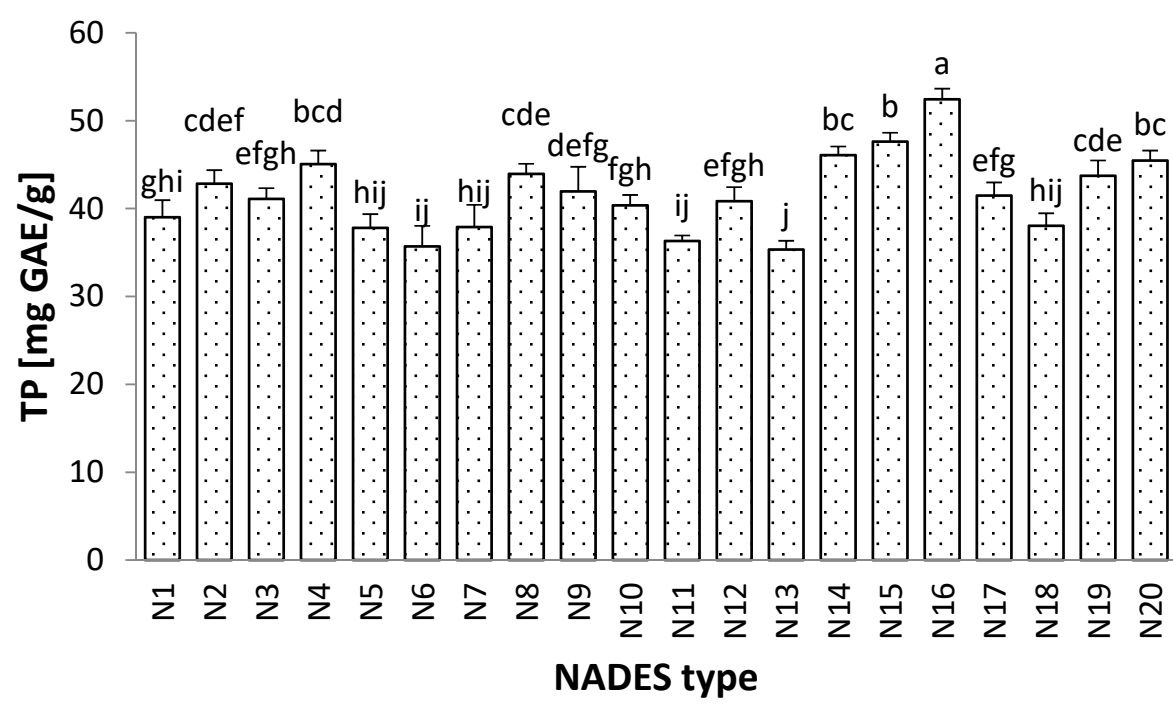

(b)

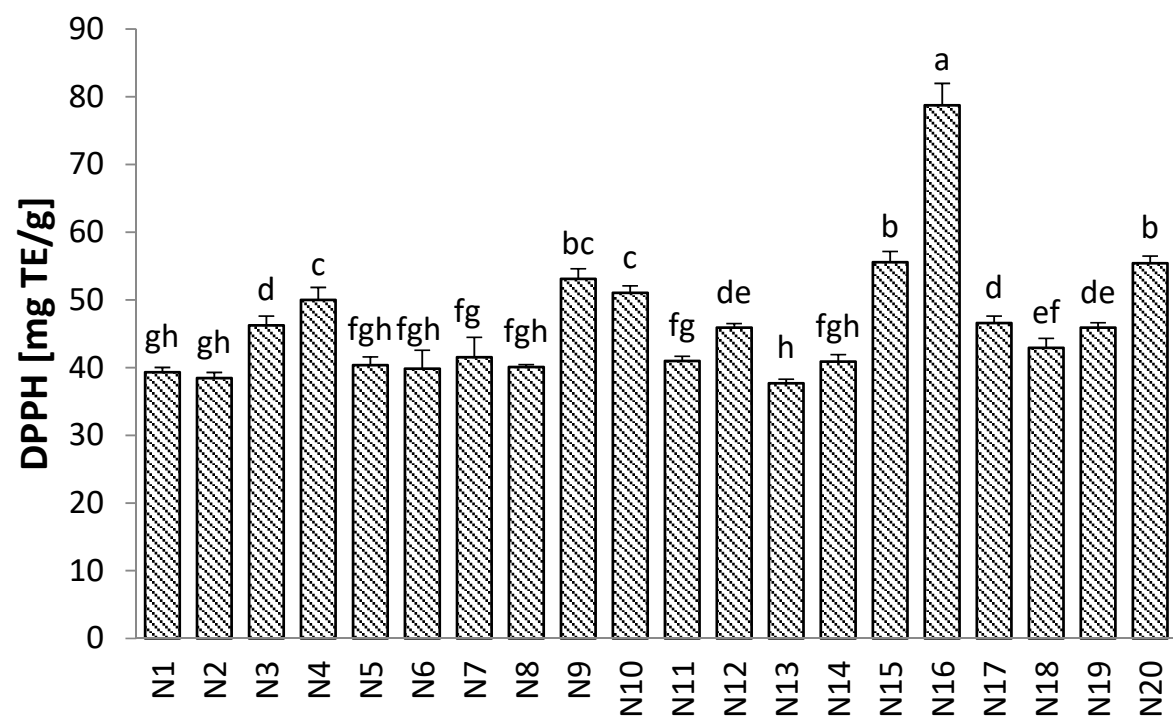

Figure 1. The effect of applied NADES on (a) total phenol content and (b) antioxidant activity toward DPPH radicals in wild thyme extracts. Results were expressed as mean \pm standard deviation (SD) and different letters represent statistically significant differences $(p<0.05)$ according to Tukey's test.

\subsection{Preliminary Study}

Besides the NADES system, the extraction of bioactive compounds could be affected by several different factors that should be optimized for each case study. Guo et al. [27] used the Plackett-Burman design for the preliminary study to narrow down the number of factors affecting the NADES extraction of mulberry anthocyanins from seven to three. These authors identified L/S ratio, homogenization time, homogenization speed, negative pressure, extraction time, temperature and number of cycles as factors for preliminary study. On the other hand, Shikov et al. [28] used the Plackett-Burman design with five factors (particle size, extraction time, temperature, extraction modulus and water content) for a preliminary study of NADES extraction of Rhodiola rosea L. Taking this into consideration, we organized a preliminary study using $2^{5-1}$ fractional factorial design with five factors. NADES type was selected as a categorical variable, while temperature, extraction time, S/L ratio and water content were numerical variables. The aim of the preliminary study was to determine the most influential NADES extraction parameters affecting TP and DPPH in order to obtain an experimental design for the optimization study. 
The experimentally observed values of target responses (TP and DPPH) obtained in the 16 runs of the preliminary study are given in Table 1 . TP ranged from 43.31 to $64.24 \mathrm{mg}$ GAE/g, suggesting that TP could be improved by variation of other extraction parameters. This was a similar case with DPPH since experimental values were in the range of 37.59-91.16 mg TE/g. The lowest and highest values of TP and DPPH were observed at the same experimental runs (run 13 and run 12, respectively), confirming the positive linear correlation observed between TP and DPPH in the first step of this research.

The TP and DPPH data were fitted to an interaction model given in Equation (1) and influence analysis was determined using Pareto charts. It is evident that NADES type exhibited the strongest impact on the target responses, while its influence was followed by the L/S ratio, temperature and extraction time. The influence of these four factors was significant according to t-values, while the impact of water content was insignificant (Figure 2). It should be highlighted that temperature-NADES type interaction also exhibited a significant influence on both responses. Since NADES exhibited a significant impact on TP and DPPH and since notably higher values of target responses were obtained using N16, this solvent system (Pro-Gly- $\mathrm{H}_{2} \mathrm{O} ; 1: 2: 1$ ) was selected for the optimization study. Since water content in the NADES mixture did not exhibit a significant effect on TP and DPPH, water content was fixed at $20 \%$ to be used in further experiments. Besides downsizing the number of extraction factors from five to three, the preliminary study was used for the determination of the experimental domain to be used in further steps. The influence of independent variables can be observed in Figure S1 (Supplementary Materials). A positive linear influence could be observed for temperature, extraction time and L/S ratio (Figure S1). Several recent NADES applications used different approaches to organize the optimization study. Doldolova et al. [29] investigated NADES extraction of antioxidants from turmeric and performed initial screening of five NADES solvents. Further, they organized the RSM study in a similar range of temperature $\left(45-60-75^{\circ} \mathrm{C}\right)$; however, they combined NADES extraction with microwave-assisted extraction (MAE) and the range of the extraction time and L/S ratio were 5-30 min and 10-20 mL/g. Similarly, screening of the NADES type was followed by RSM optimization with extraction time $\left(40-100{ }^{\circ} \mathrm{C}\right)$, water content in NADES (10-50\%) and molar ratio between $\mathrm{LA}$ and $\mathrm{ChCl}(1-5 \mathrm{~mol} / \mathrm{mol})$ in the extraction of polyphenols from Helichrysum arenarium L. [30].

Taking into consideration trends of the influence of the extraction parameters obtained in the preliminary study and recent literature data on NADES extraction, the experimental plan for the RSM optimization study was generated with experimental domain for temperature, extraction time and $\mathrm{L} / \mathrm{S}$ ratio set at 40-55-70 ${ }^{\circ} \mathrm{C}, 60-120-180 \mathrm{~min}$ and 10-20-30 g NADES/g of plant sample, respectively, while NADES type (N16) and water content (20\%) were held constant in this step.

\subsection{Optimization Study}

\subsubsection{Accuracy of Fit and Influence Analysis}

Experimental results of investigated responses (TP, TF, DPPH, FRAP and ABTS) obtained under different sets of NADES extraction parameters (temperature, extraction time and L/S ratio) using a face-centered central composite experimental design are given in Table 2. Data was fitted to a quadratic polynomial model (Equation (2)), while ANOVA (F-test) and descriptive statistics $\left(\mathrm{R}^{2}\right.$ and $\mathrm{CV}$ ) were applied in order to determine goodness of fit (Table 3). Generally, high values of $\mathrm{R}^{2}$ were observed for TP, TF and DPPH $(0.922,0.905$ and 0.984 , respectively), while moderately high values were obtained in the case of FRAP and ABTS (0.832 and 0.803), suggesting the accordance between the model and experimental results. Moreover, TP and DPPH results were followed by negligible CV (4.72 and 3.69\%), which points out proper reproducibility of the developed model systems. Moderately high CV values for TF, FRAP and ABTS (17.24, 12.88 and 13.48\%, respectively) suggest that higher dispersion of the data could occur. Furthermore, thorough information about model fitness could be obtained by the lack-of-fit testing since insignificant lack-of-fit confirms the assumption of the constant variance, which means that variance is a model-independent 
measure of the pure error [31]. It was shown that the quadratic model provides adequate representation of experimental data according to statistically insignificant $p$-values for the lack-of-fit $(p>0.05)$ for the TP, DPPH, FRAP and ABTS. Slight disagreement in statistical parameters for certain responses suggests that experimental validation must be performed in order to confirm the developed mathematical models. Several other studies showed that RSM could be adequately used for optimization of NADES-based extractions, i.e., NADES extraction combined with UAE for isolation of Helichrysum arenarium polyphenols [30], NADES extraction combined with MAE for isolation of turmeric antioxidants [29], recovery of mulberry anthocyanins [27] and wine lees anthocyanins [32], and isolation of TP from Hibiscus sabdariffa [33].
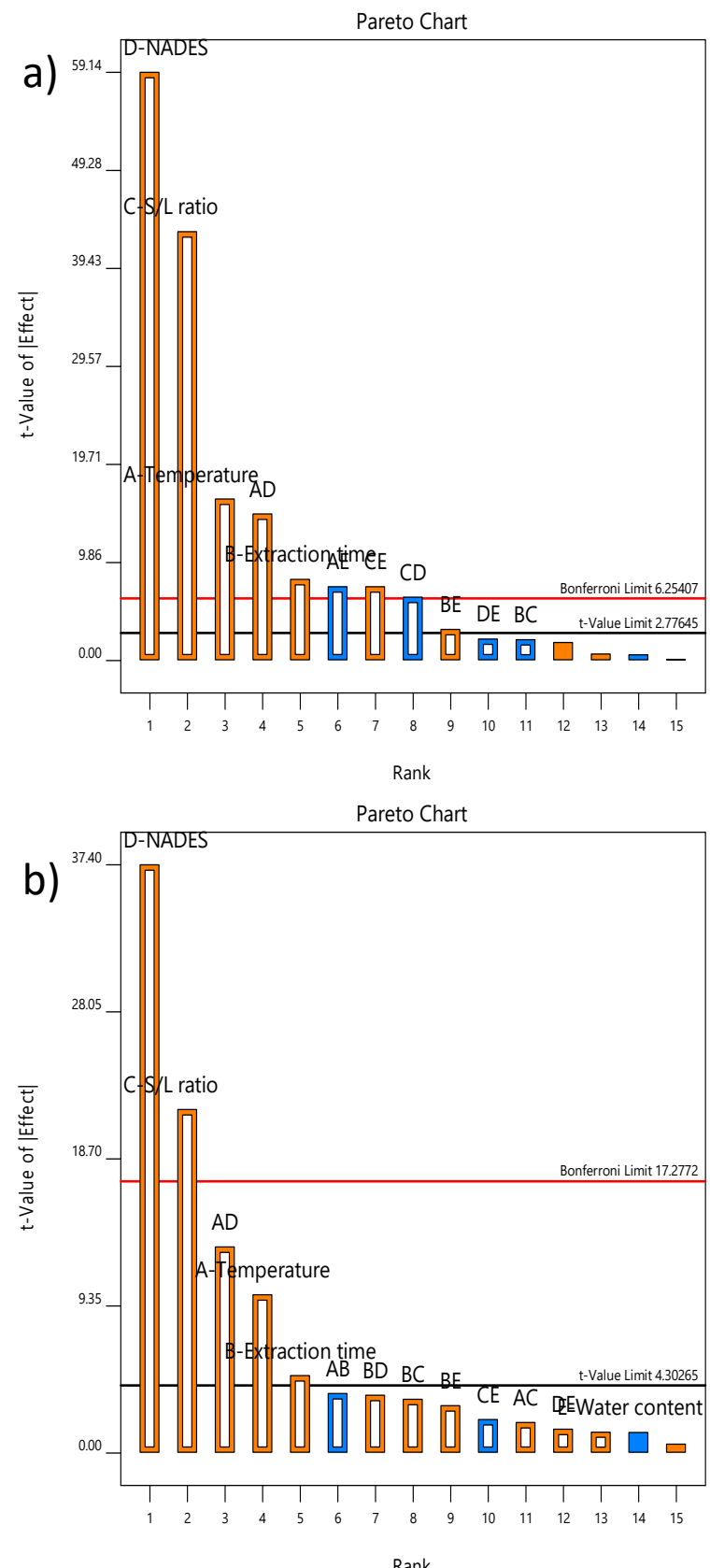

Figure 2. Pareto chart exhibiting effects of temperature (A), extraction time (B), L/S ratio (C), NADES (D) and water content (E) on (a) TP and (b) DPPH. 
Table 2. Face-centered central composite experimental design with real and coded NADES extraction parameters and experimentally obtained values of investigated target responses (TP, TF, DPPH, FRAP and ABTS).

\begin{tabular}{|c|c|c|c|c|c|c|c|c|c|c|c|}
\hline \multirow{2}{*}{ Run } & \multicolumn{2}{|c|}{ Factor 1} & \multicolumn{2}{|c|}{ Factor 2} & \multicolumn{2}{|c|}{ Factor 3} & \multirow{2}{*}{$\begin{array}{c}\text { Response } 1 \\
\text { TP } \\
{[\mathrm{mg} \mathrm{GAE} / \mathrm{g}]}\end{array}$} & \multirow{2}{*}{$\begin{array}{c}\text { Response } 2 \\
\text { TF } \\
{[\mathrm{mg} \mathrm{CE} / \mathrm{g}]}\end{array}$} & \multirow{2}{*}{$\begin{array}{c}\text { Response } 3 \\
\text { DPPH } \\
{[\mathrm{mg} \text { TE/g] }}\end{array}$} & \multirow{2}{*}{$\begin{array}{c}\text { Response } 4 \\
\text { FRAP } \\
{\left[\mathrm{mg} \mathrm{Fe}^{2+} / \mathrm{g}\right]}\end{array}$} & \multirow{2}{*}{$\begin{array}{c}\text { Response } 5 \\
\begin{array}{c}\text { ABTS } \\
{[\mathrm{mg} \mathrm{TE} / \mathrm{g}]}\end{array}\end{array}$} \\
\hline & A: $T$ & ture & B: Extr & Time & $\begin{array}{r}\mathrm{C} \\
\lg \mathrm{N}\end{array}$ & $\begin{array}{l}\text { lo } \\
\text { DW] }\end{array}$ & & & & & \\
\hline 1 & 1 & 70 & 1 & 180 & -1 & 10 & 59.69 & 4.82 & 110.59 & 37.63 & 125.42 \\
\hline 2 & -1 & 40 & -1 & 60 & -1 & 10 & 49.13 & 10.29 & 78.63 & 19.85 & 70.81 \\
\hline 3 & 0 & 55 & 0 & 120 & 0 & 20 & 61.64 & 23.48 & 143.49 & 42.03 & 140.84 \\
\hline 4 & 0 & 55 & 1 & 180 & 0 & 20 & 65.69 & 22.29 & 145.81 & 33.75 & 120.62 \\
\hline 5 & 0 & 55 & 0 & 120 & 0 & 20 & 62.53 & 23.54 & 144.10 & 33.29 & 116.87 \\
\hline 6 & 0 & 55 & 0 & 120 & 0 & 20 & 59.14 & 23.48 & 145.61 & 33.19 & 115.34 \\
\hline 7 & 0 & 55 & 0 & 120 & 1 & 30 & 66.74 & 20.55 & 174.14 & 35.56 & 113.90 \\
\hline 8 & 0 & 55 & 0 & 120 & 0 & 20 & 59.34 & 23.02 & 147.25 & 42.61 & 139.94 \\
\hline 9 & -1 & 40 & 1 & 180 & 1 & 30 & 54.86 & 24.00 & 156.07 & 25.62 & 84.75 \\
\hline 10 & 0 & 55 & 0 & 120 & 0 & 20 & 59.61 & 23.22 & 152.76 & 44.70 & 147.87 \\
\hline 11 & -1 & 40 & 1 & 180 & -1 & 10 & 47.38 & 10.37 & 89.46 & 21.56 & 75.29 \\
\hline 12 & 1 & 70 & 0 & 120 & 0 & 20 & 70.01 & 22.70 & 155.44 & 37.51 & 118.08 \\
\hline 13 & 1 & 70 & -1 & 60 & 1 & 30 & 67.74 & 20.33 & 188.08 & 38.12 & 119.57 \\
\hline 14 & -1 & 40 & -1 & 60 & 1 & 30 & 53.82 & 24.66 & 153.19 & 24.09 & 77.97 \\
\hline 15 & 1 & 70 & -1 & 60 & -1 & 10 & 57.65 & 6.01 & 125.61 & 33.17 & 100.35 \\
\hline 16 & 0 & 55 & 0 & 120 & -1 & 10 & 53.40 & 5.20 & 120.33 & 33.38 & 100.96 \\
\hline 17 & 1 & 70 & 1 & 180 & 1 & 30 & 71.43 & 19.34 & 188.01 & 42.00 & 124.55 \\
\hline 18 & -1 & 40 & 0 & 120 & 0 & 20 & 48.27 & 14.37 & 116.73 & 23.29 & 77.56 \\
\hline 19 & 0 & 55 & -1 & 60 & 0 & 20 & 57.82 & 24.65 & 143.44 & 34.08 & 98.24 \\
\hline
\end{tabular}

Contribution analysis pointed out that the linear term of temperature was the most prominent factor $(p<0.05)$ affecting the TP, DPPH, FRAP and ABTS with a contribution higher than $50 \%$ (Figure 3). The quadratic term of temperature exhibited a significant effect on DPPH, while its effect on FRAP and ABTS was moderate $(p<0.1)$ (Table S1). Temperature was also found to be the most influential parameter in an RSM study focused on NADES combined with MAE for the isolation of bioactive compounds from turmeric [29]. On the other hand, L/S ratio was the most dominant NADES extraction parameter that affected TF and DPPH with a contribution above $60 \%$ (Figure 3), while the quadratic term of this factor was statistically significant $(p<0.05)$ only in the case of TF with a $20.47 \%$ contribution. It could be observed that neither the extraction time terms nor any interaction caused a significant impact on any response (Table S1). According to Guo et al. [27], L/S ratio exhibited significant, while the extraction time effect was insignificant in the RSM study focused on the NADES extraction of mulberry anthocyanins.

Contribution analysis pointed out that the linear term of temperature was the most prominent factor $(p<0.05)$ affecting TP, DPPH, FRAP and ABTS with a contribution higher than $50 \%$ (Figure 3 ). The quadratic term of temperature exhibited a significant effect on DPPH.

For the calculation of regression coefficients in polynomial equation, the method of least square was used and gave the predictive model equations that are as follows:

$$
\begin{gathered}
\mathrm{TP}=60.847 .31 \mathrm{~A}+1.29 \mathrm{~B}+4.73 \mathrm{C}+0.81 \mathrm{AB}+1.21 \mathrm{AC}+0.55 \mathrm{BC}-2.19 \mathrm{~A}^{2}+0.43 \mathrm{~B}^{2}-1.25 \mathrm{C}^{2} \\
\mathrm{TF}=22.23-1.05 \mathrm{~A}-0.51 \mathrm{~B}+7.22 \mathrm{C}-0.20 \mathrm{AB}+0.11 \mathrm{AC}-0.07 \mathrm{BC}-2.29 \mathrm{~A}^{2}+2.64 \mathrm{~B}^{2}-7.95 \mathrm{C}^{2} \\
\mathrm{DPPH}=146.38+17.36 \mathrm{~A}+0.10 \mathrm{~B}+33.49 \mathrm{C}-3.60 \mathrm{AB}-0.16 \mathrm{AC}+0.88 \mathrm{BC}-9.99 \mathrm{~A}^{2}-1.44 \mathrm{~B}^{2}+1.17 \mathrm{C}^{2} \\
\mathrm{FRAP}=37.55+7.40 \mathrm{~A}+1.12 \mathrm{~B}+1.98 \mathrm{C}+0.64 \mathrm{AB}+0.13 \mathrm{AC}-0.09 \mathrm{BC}-5.13 \mathrm{~A}^{2}-1.61 \mathrm{~B}^{2}-1.05 \mathrm{C}^{2} \\
\mathrm{ABTS}=124.42+20.12 \mathrm{~A}+6.37 \mathrm{~B}+4.79 \mathrm{C}+2.35 \mathrm{AB}+0.22 \mathrm{AC}-2.22 \mathrm{BC}-16.91 \mathrm{~A}^{2}-5.30 \mathrm{~B}^{2}-7.30 \mathrm{C}^{2}
\end{gathered}
$$

\subsubsection{Polyphenol Content, Antioxidant Activity and Effect of NADES}

Extraction Parameters

To the best of our knowledge, NADES extraction was not previously optimized for T. serpyllum. TP varied between 47.38 and $71.43 \mathrm{mg}$ GAE/g (Table 2) depending on the different set of NADES extraction conditions. The highest TP was observed in run 17, which was obtained at high levels of independent extraction factors $\left(70^{\circ} \mathrm{C}, 180 \mathrm{~min}\right.$ and $30 \mathrm{~g}$ NADES/g plant material). On the other hand, recent work suggested that extraction 
of polyphenols from wild thyme herbal dust was optimized by other techniques, such as conventional solid-liquid extraction, ultrasound-extraction (UAE) and pressurized-liquid extraction (PLE) [7,8]. According to Mrkonjic et al. [7], ethanol concentration was an optimized factor for conventional extraction of T. serpyllum herbal dust and the highest TP observed was $17.35 \mathrm{mg} \mathrm{GAE} / \mathrm{g}$, while $43.88 \mathrm{mg}$ GAE/g of TP was obtained by UAE at an optimal set of temperature, extraction time and ethanol concentration. In other work, the PLE of wild thyme herbal dust was optimized in two stages (preliminary design and RSM study), and $67.46 \mathrm{mg}$ GAE/g of TP was obtained at an optimal set of PLE conditions [8]. Experiments in this work were performed with the same raw material as was used in the aforementioned references, which highlights the tremendous improvement in TP obtained by NADES extraction compared to traditional extraction and UAE, as well as considerable improvement compared to PLE. In the case of TF, experimentally measured values ranged from 4.82 to $23.54 \mathrm{mg} \mathrm{CE} / \mathrm{g}$ and it could be generally observed that high TF values were observed at the experimental runs with high TP. TF in wild thyme extracts obtained by UAE and maceration was approximately $50 \%$ of TP; however, TP results in these works were exhibited as mg CE per liter of liquid extracts [34,35], which makes it unsuitable for comparison. However, it could be observed that the TP/TF ratio obtained in this work was considerably lower (Table 2) compared to the aforementioned research studies.

Table 3. Analysis of variance (ANOVA) and descriptive statistics $\left(R^{2}\right.$ and $\left.C V\right)$ of the fitted model for all investigated responses (TP, TF, DPPH, FRAP and ABTS).

\begin{tabular}{|c|c|c|c|c|c|}
\hline Source & Sum of & $\mathrm{df}^{*}$ & Mean & F-Value & $p$-Value \\
\hline \multicolumn{6}{|l|}{$\mathbf{T P}$} \\
\hline Model & 831.71 & 9 & 92.41 & 11.7975 & 0.00055 \\
\hline Residual & 70.50 & 9 & 7.83 & & \\
\hline Lack of Fit & 61.07 & 5 & 12.21 & 5.1803 & 0.06809 \\
\hline Pure Error & 9.43 & 4 & 2.36 & & \\
\hline Cor Total & 902.21 & 18 & & & \\
\hline $\mathrm{R}^{2}$ & 0.922 & & & & \\
\hline CV [\%] & 4.72 & & & & \\
\hline \multicolumn{6}{|l|}{ TF } \\
\hline Model & 844.22 & 9 & 93.80 & 9.4944 & 0.00127 \\
\hline Residual & 88.92 & 9 & 9.88 & & \\
\hline Lack of Fit & 88.72 & 5 & 17.74 & 359.7893 & $<0.0001$ \\
\hline Pure Error & 0.20 & 4 & 0.05 & & \\
\hline Cor Total & 933.14 & 18 & & & \\
\hline$R^{2}$ & 0.905 & & & & \\
\hline CV [\%] & 17.24 & & & & \\
\hline \multicolumn{6}{|l|}{ DPPH } \\
\hline Model & $14,833.37$ & 9 & 1648.15 & 61.0444 & $<0.0001$ \\
\hline Residual & 242.99 & 9 & 27.00 & & \\
\hline Lack of Fit & 187.76 & 5 & 37.55 & 2.71975 & 0.17690 \\
\hline Pure Error & 55.23 & 4 & 13.81 & & \\
\hline Cor Total & $15,076.36$ & 18 & & & \\
\hline $\mathrm{R}^{2}$ & 0.984 & & & & \\
\hline CV [\%] & 3.69 & & & & \\
\hline \multicolumn{6}{|l|}{ FRAP } \\
\hline Model & 829.49 & 9 & 92.17 & 4.9684 & 0.01280 \\
\hline Residual & 166.95 & 9 & 18.55 & & \\
\hline Lack of Fit & 45.98 & 5 & 9.20 & 0.3041 & 0.88809 \\
\hline Pure Error & 120.97 & 4 & 30.24 & & \\
\hline Cor Total & 996.45 & 18 & & & \\
\hline $\mathrm{R}^{2}$ & 0.832 & & & & \\
\hline CV [\%] & 12.88 & & & & \\
\hline \multicolumn{6}{|l|}{ ABTS } \\
\hline Model & 7899.47 & 9 & 877.72 & 4.0763 & 0.02406 \\
\hline Residual & 1937.89 & 9 & 215.32 & & \\
\hline Lack of Fit & 1038.55 & 5 & 207.71 & 0.9238 & 0.54581 \\
\hline Pure Error & 899.34 & 4 & 224.84 & & \\
\hline Cor Total & 9837.36 & 18 & & & \\
\hline$R^{2}$ & 0.803 & & & & \\
\hline CV [\%] & 13.48 & & & & \\
\hline
\end{tabular}

* degrees of freedom. 

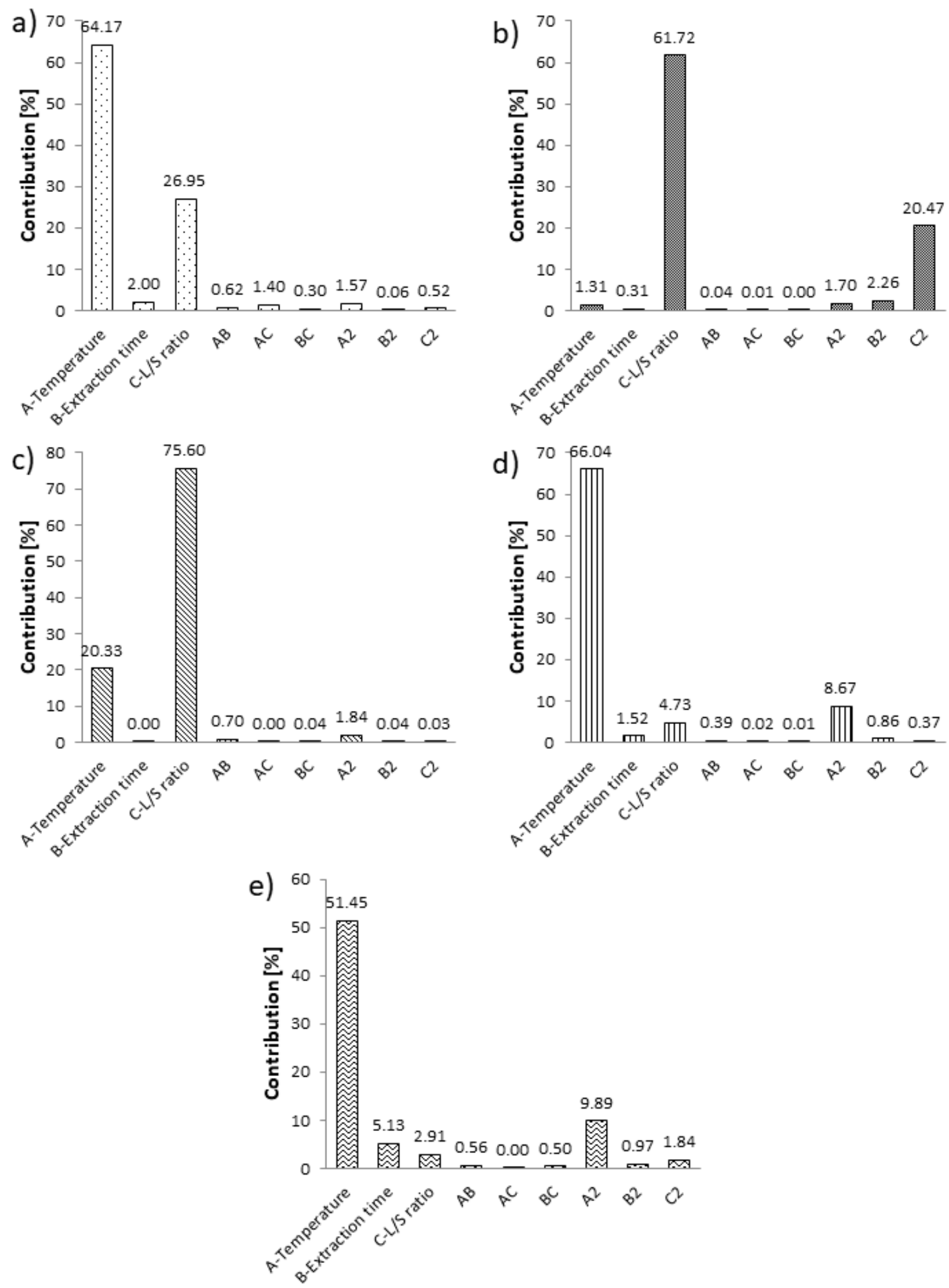

Figure 3. Contribution plots for the linear, interaction and quadratic terms on (a) TP, (b) TF, (c) DPPH, (d) FRAP and (e) ABTS.

Fast in vitro assays were selected as model systems for the determination of antioxidant activity. Experimentally observed values obtained by the DPPH, FRAP and ABTS assays were in the following ranges: 78.63-188.01 mg TE/g, 19.85-44.70 $\mathrm{mg} \mathrm{Fe} \mathrm{Fe}^{2+} / \mathrm{g}$ and 70.81-147.87 mg TE/g, respectively. It could be observed that the lowest values obtained 
by all three assays were obtained in run 2 at a lower level of all three factors $\left(40{ }^{\circ} \mathrm{C}, 60 \mathrm{~min}\right.$ and $10 \mathrm{~g}$ NADES/g DW). On the other hand, the highest activity toward DPPH radicals was observed in run 17, the same extract where the highest TP was obtained, suggesting that polyphenols were the main compounds responsible for antioxidant activity. In vitro antioxidant activity in wild thyme extracts obtained by various extraction techniques (conventional solid-liquid, UAE and PLE) was previously investigated elsewhere and the results were expressed as $\mathrm{mM}$ equivalents per $100 \mathrm{~g}$ plant material [7,8]. However, when these results are calculated on the same units as was given in this work, the radical scavenging capacity of T. serpyllum extracts obtained by conventional solid-liquid extraction, UAE and PLE were 34.37, 63.35 and $79.42 \mathrm{mg} \mathrm{TE} / \mathrm{g}$ and it could be noted that NADES extraction provides tremendous upgrade on antioxidant capacity of wild time extracts in comparison with other traditional and emerging extraction techniques (Table 2). On the other hand, FRAP results were 43.18 and $47.96 \mathrm{mg} \mathrm{Fe}^{2+} / \mathrm{g}$ and ABTS results were 131.17 and $173.79 \mathrm{mg}$ TE/g observed in wild thyme extracts obtained by UAE and PLE techniques, respectively $[7,8]$. It could be noted that NADES extraction provides very similar results of reducing power and scavenging capacity of $\mathrm{ABTS}^{+}$radicals as other emerging extraction techniques.

Since no significant interactions were observed (Table S1), impacts of NADES extraction parameters were presented in one-factor graphs given in Figure 4.

(a)

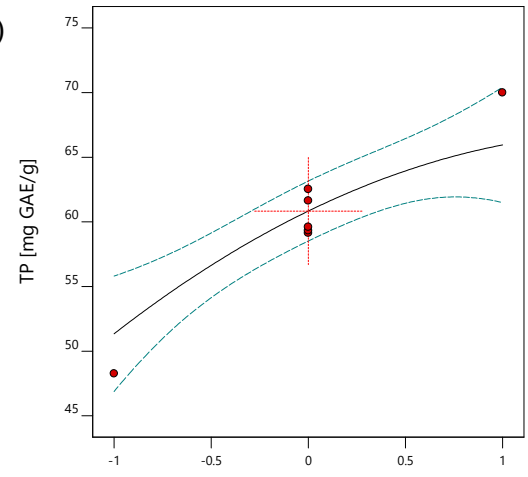

(b)

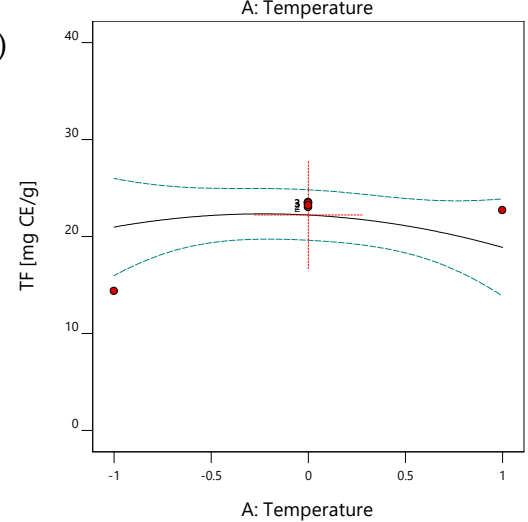

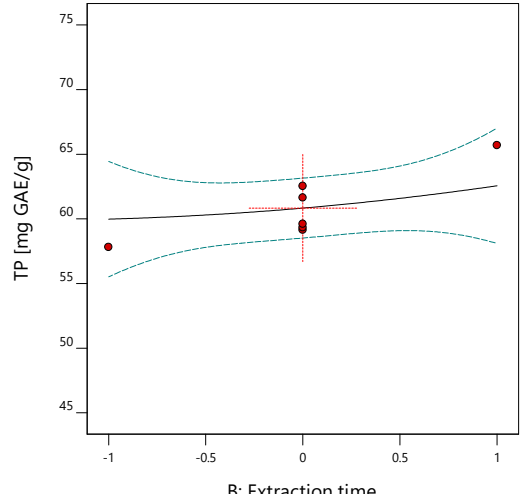

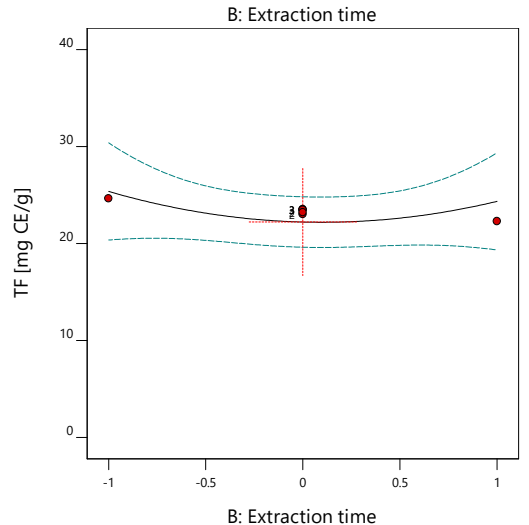

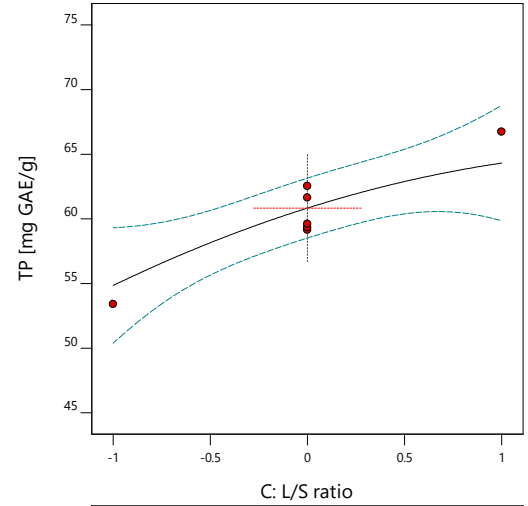

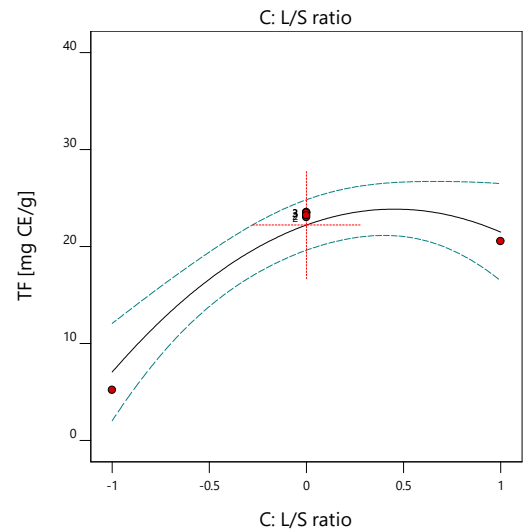

Figure 4. The effect of NADES extraction parameters (temperature, extraction time and L/S ratio) on (a) TP and (b) TF.

Temperature has often been considered the most important extraction factor, despite the applied technique. The linear term of temperature exhibited a strong positive effect on TP, FRAP and ABTS, which could be explained by different phenomena occurring within the process. Increased temperature decreases surface tension and the viscosity of the solvents, which is particularly important for viscous fluids, such as NADES mixtures. This will result in the wetting of the sample and easier penetration of the solvent in the matrix [36]. At the same time, elevated temperature will ease the desorption and dissolution of the target compounds by preventing adhesion to the solid matrix weakening 
physicochemical interactions, such as van der Waals forces, hydrogen bonding, dipole moment and electrostatic interactions [29]. The positive impact of the linear term of temperature was often reported in other works focused on NADES-based processes optimized by RSM [33]. However, elevated temperature could cause chemical degradation of either NADES or target compounds and some reports suggested yellowing of the solvent, which is considered to be degradation of the NADES at temperature above $75^{\circ} \mathrm{C}$ [29]. Therefore, a high level of temperature would be optimal for the maximized recovery of polyphenols (TP) and antioxidant activity Figure $4 \mathrm{a}$ and Figure S2), while no significant effect of temperature on TF was observed (Figure 4 b).

The temperature effect was followed by the significant positive impact of L/S ratio which is in accordance with mass transfer laws. A higher L/S ratio will provide a better driving force due to the higher concentration gradient between NADES and the plant matrix [29]. However, an insufficient L/S ratio could cause various equilibriums in the process and consequently higher resistance to a mass transfer [37]. The impact of L/S ratio was in accordance with other case studies where NADES extraction was optimized using experimental design $[27,33]$. However, a tremendous L/S ratio would diminish the content of the target compounds in the extracts obtained by NADES, which would limit their utilization in other food, cosmetics or pharmaceutical products. Therefore, a high level of L/S ratio (30 g NADES/g DW) would be optimal for the recovery of wild thyme antioxidants Figure 4 and Figure S2), which is the range that was generally used in similar NADES-RSM studies [27]. Furthermore, a significant effect of the quadratic term of L/S ratio on TF can be clearly observed in Figure $4 \mathrm{~b}$.

\subsubsection{NMR Characterization of the Optimal NADES}

The NMR experiments were performed in individual components used for the preparation of optimal NADES (N16; Pro-Gly- $\mathrm{H}_{2} \mathrm{O} ; 1: 2: 1$ ) and a mixture used for the extraction. ${ }^{1} \mathrm{H}$ spectra were overlaid to facilitate the observation of differences between chemical shifts of the individual components and after NADES formation (Figure 5). It is observed that all the groups in the NADES formulation suffer from a slight deviation in the chemical shift, which suggests a different spatial distribution of the molecules. Although in NOESY we only observe signals in the -NH group of L-proline and $-\mathrm{CH}_{2}$ of glycerine, we can confirm a proximity between the two components of NADES and predict that there are interactions occurring in - $\mathrm{OH}$ and - $\mathrm{NH}$ groups from glycerine and L-proline.

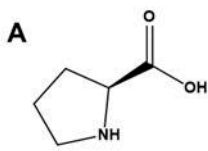

A
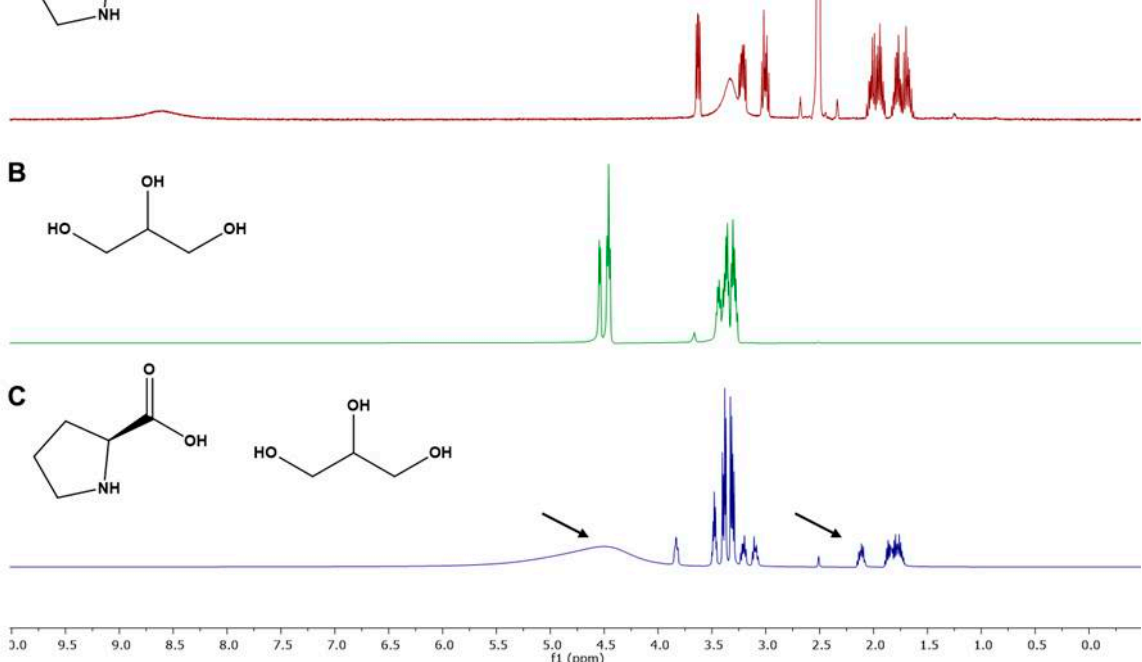

Figure 5. ${ }^{1} \mathrm{H}-\mathrm{NMR}$ spectra of (A) L-proline, (B) glycerine and (C) N16 (20\% w/w of water). 


\subsubsection{Optimization and Validation}

In order to simultaneously maximize polyphenol content (TP and TF) and antioxidant activity (DPPH, FRAP and ABTS) and to determine the best set of NADES extraction parameters, desirability function was used and its value was 0.887 . Multi-response optimization provided the following optimal conditions: temperature of $65^{\circ} \mathrm{C}$, extraction time of $180 \mathrm{~min}$ and L/S ratio of $28 \mathrm{~g}$ NADES/g DW. Predicted and experimental values of investigated responses are presented in Table 4 . After experimental verification at optimal conditions, the agreement between experimental and predicted values was very good. Minor disagreement was observed in the case of TF and ABTS since experimentally observed values were slightly lower compared to calculated predictions (Table 4). This leads to the conclusion that applied quadratic models are validated and could be used for point prediction within the investigated experimental domain. It should be highlighted that performed optimization in three steps provided an increase in TP and DPPH for approximately $26 \%$ and $56 \%$, respectively, compared to the highest values obtained in the first step (screening of the extraction solvent). Since it has been previously confirmed that NADES extraction provides a significant upgrade in the recovery of polyphenols from wild thyme compared to conventional extraction, UAE [7] and PLE [8], it could be concluded that NADES extraction is an efficient method and emerging approach for the recovery of T. serpyllum antioxidants.

Table 4. Experimental validation of RSM optimization for NADES extraction of polyphenols and antioxidants from wild thyme.

\begin{tabular}{|c|c|c|c|c|c|}
\hline \multirow{2}{*}{$\begin{array}{l}\text { Input and Output } \\
\text { Parameters }\end{array}$} & \multirow{2}{*}{ Goal } & \multirow{2}{*}{ Lower Limit } & \multirow{2}{*}{ Upper Limit } & $\begin{array}{l}\text { Predicted } \\
\text { Values }\end{array}$ & \multirow{2}{*}{$\begin{array}{c}\text { Experimental Values } \\
\text { Optimal Conditions }\end{array}$} \\
\hline & & & & Optimal Conditions & \\
\hline Temperature $\left[{ }^{\circ} \mathrm{C}\right]$ & is in range & 40 & 70 & 65 & 65 \\
\hline Extraction time [min] & is in range & 60 & 180 & 180 & 180 \\
\hline $\begin{array}{c}\mathrm{L} / \mathrm{S} \text { ratio }[\mathrm{g} \\
\mathrm{NADES} / \mathrm{g} \text { DW] }\end{array}$ & is in range & 10 & 30 & 28 & 28 \\
\hline $\mathrm{TP}$ [mg GAE/g] & maximize & 43.38 & 71.43 & 71.43 & $71.43 \pm 1.17$ \\
\hline TF [mg CE/g] & maximize & 4.82 & 24.66 & 22.81 & $19.43 \pm 0.20$ \\
\hline DPPH [mg TE/g] & maximize & 78.63 & 188.08 & 179.52 & $188.01 \pm 11.19$ \\
\hline FRAP $\left[\mathrm{mg} \mathrm{Fe}^{2+} / \mathrm{g}\right]$ & maximize & 19.85 & 44.70 & 41.09 & $42.00 \pm 0.28$ \\
\hline ABTS [mg TE/g] & maximize & 70.80 & 147.87 & 130.06 & $124.55 \pm 3.25$ \\
\hline
\end{tabular}

HPLC analysis of major polyphenols was performed on NADES extract obtained under optimal conditions, and results are given in Table 5. Rosmarinic acid was the predominant compound present in wild thyme extract with particularly high content $(524.18 \mathrm{mg} / 100 \mathrm{~g})$, which is in accordance with previously published data on wild thyme extracts [2,34]. On the other hand, luteolin, epicatechin and quercetin were major flavonoids quantified in this sample. Previous studies confirmed that all compounds quantified in this work were identified in wild thyme extracts obtained by UAE [7] and PLE [8]. HPLC results showed that a particularly high content of phenolic acids and flavonoids could be obtained by NADES extraction.

Table 5. Content of major polyphenols (phenolic acids and flavonoids) in wild thyme extract obtained under optimal conditions.

\begin{tabular}{ccc}
\hline No. & Compound & Content $[\mathbf{m g} / \mathbf{1 0 0} \mathbf{g}]$ \\
\hline 1. & Gallic acid & 20.61 \\
2. & Caffeic acid & 25.83 \\
3. & Epicatechin & 21.06 \\
4. & Rosmarinic acid & 524.18 \\
5. & Luteolin & 28.27 \\
6. & Quercetin & 42.27 \\
\hline
\end{tabular}




\section{Materials and Methods}

\subsection{Plant Material}

T. serpyllum L. used as a raw material in the present study represents a by-product from filter-tea production that was kindly donated by the factory Macval D.O.O. from Novi Sad (Serbia). Plant material was harvested and processed in 2017. Since its mean particle size is less than $0.315 \mathrm{~mm}$, it cannot be packed in filter bags; therefore, it is considered industrial waste. Dried herbal dust was stored in paper bags at $20{ }^{\circ} \mathrm{C}$.

\subsection{Chemicals}

From Sigma-Aldrich (Steinheim, Germany), the following reagents were obtained: Folin-Ciocalteu reagent, Trolox, gallic acid, 2,2-diphenyl-1-picrylhydrazyl (DPPH), 2,4,6tris(2-pyridyl)-s-triazine ( $\geq 99.0 \%)$ (TPTZ), glucose, sucrose, choline chloride, glycerin, fructose, lactic acid (85\% purity with 15\% water), L-proline, 1,2-propanediol and citric acid. 2,2'-Azino-bis(3-ethylbenzothiazoline-6-sulfonic acid) diammoniumsalt (98\%) was purchased from J\&K, Scientific Ltd., Beijing, China. L(+)-tartaric acid and malic acid were obtained from Scharlab (Barcelona, Spain), while anhydrous betaine was purchased from Tokyo Chemical Industry (Tokyo, Japan). Additionally, sodium carbonate anhydrous and ferric chloride hexahydrate were supplied from Centrohem, Stara Pazova, Serbia. Acetic acid $(99.8 \%)$ and potassium peroxydisulfate were purchased from Lach-Ner, Neratovice, Czech Republic, while sodium acetate anhydrous was purchased from Kemika, Zagreb, Croatia. Polyphenol standards used for HPLC analysis (gallic acid, caffeic acid, epicatechin, rosmarinic acid, luteolin and quercetin) were all purchased from Sigma-Aldrich (Steinheim, Germany). Ultrapure water was obtained by a Milli-Q Plus system (EMD Millipore, Billerica, MA, USA). All other chemicals were of analytical reagent grade.

\subsection{NADES Preparation}

All NADES used in the present study are composed of organic acids and polyols as hydrogen-bond donors and hydrogen-bond acceptors with different molar ratios (Table 6). According to Ekaterina et al. [38], NADES could be efficiently formulated for the recovery of both hydrophilic and lipophilic compounds. The selection and formulation of NADES used in this work was based on applications of NADES extraction for recovery of polyphenols from different plant matrices found in recent literature [39-42]. In total, twenty different NADES were selected for the screening study, and they were prepared in a water bath at $80{ }^{\circ} \mathrm{C}$ placed on a magnetic stirrer hot plate. Mixing lasted approximately 10 min until stable transparent liquid was formed. All created NADES were stable at room temperature $\left(\approx 20{ }^{\circ} \mathrm{C}\right)$ up to more than seven days. Final water content in NADES was mathematically calculated ( 20 or $25 \%$ ) and accordingly adjusted for each extraction run according to our previous study [39]. Initial water content in chemicals and reagents was also taken into consideration for calculation.

\subsection{NADES Extraction and Experimental Plan}

NADES extraction of wild thyme polyphenols was performed in three steps: (1) screening of extraction solvent, (2) preliminary study and (3) response surface methodology (RSM) optimization. The experimental plan is given in Table 7.

Experiments for the screening of extraction solvent were performed in a water bath at $50 \pm 1{ }^{\circ} \mathrm{C}$ placed on a magnetic stirrer hot plate with thermocouple for temperature regulation. Solvent (NADES: N1-N20) and plant matrix (0.05 g) were placed together with a small magnet into a glass extraction vial with a 1:20 (m/m) sample to solvent ratio. The vial was tightly closed with a cap and immersed in the water bath for $60 \mathrm{~min}$. Water $(4 \mathrm{~mL})$ was added after the extraction to ease separation of solid and liquid phases, and samples were centrifuged for $15 \mathrm{~min}$ at $4000 \mathrm{rpm}$. The supernatant was separated from solid plant residue and stored in a fridge at $4{ }^{\circ} \mathrm{C}$ until the analysis of total phenol content (TP) and antioxidant activity toward DPPH radicals. 
Table 6. Chemical content of applied NADES mixtures in the screening of extraction solvent.

\begin{tabular}{|c|c|c|c|}
\hline Code & Content & Molar Ratio & Water Content [\%] \\
\hline N1 & Citric acid (CA)-glucose (Glu) & $1: 1$ & - \\
\hline N2 & Citric acid (CA)-sucrose (Suc) & $1: 1$ & - \\
\hline N3 & Citric acid (CA)-betaine (Bet)-water $\left(\mathrm{H}_{2} \mathrm{O}\right)$ & $1: 1: 1$ & 5.50 \\
\hline $\mathrm{N} 4$ & Choline chloride (ChCl)-glucose (Glu) & $1: 1$ & - \\
\hline N5 & Glycerin (Gly)-betaine (BET) & $2: 1$ & - \\
\hline N6 & Betaine (Bet)-glycerine (Gly)-water $\left(\mathrm{H}_{2} \mathrm{O}\right)$ & $1: 2: 1$ & 5.64 \\
\hline N7 & Betaine (Bet)-glucose $(\mathrm{Glu})$ & $1: 1$ & - \\
\hline N8 & Glycerin (Gly)-fructose (Fru) & $4: 1$ & - \\
\hline N9 & Choline chloride (ChCl)-glycerin (Gly) & $1: 2$ & - \\
\hline N10 & Choline chloride $(\mathrm{ChCl})$-glycerin $(\mathrm{Gly})$-water $\left(\mathrm{H}_{2} \mathrm{O}\right)$ & 2:1:1 & 5.27 \\
\hline N11 & Lactic acid (LA)-glucos -water $\left(\mathrm{H}_{2} \mathrm{O}\right)$ & $5: 1: 3$ & 7.89 \\
\hline N12 & Choline chloride $(\mathrm{ChCl})$-lactic acid (LA) & $1: 4$ & 11.23 \\
\hline N13 & Glucose (Glu)-tartaric acid (TA) & $1: 1$ & - \\
\hline N14 & Lactic acid (LA)-fructose (Fru) & $5: 1$ & 11.16 \\
\hline N15 & L-proline (Pro)-lactic acid (LA) & $1: 2$ & 9.69 \\
\hline N16 & L-proline (Pro)-glycerin (Gly)-water $\left(\mathrm{H}_{2} \mathrm{O}\right)$ & $1: 2: 1$ & 5.68 \\
\hline N17 & Malic acid (MA)-betaine (Bet)-water $\left(\mathrm{H}_{2} \mathrm{O}\right)$ & $2: 1: 5$ & 18.95 \\
\hline N18 & Tartaric acid (TA)-betaine (Bet)-water $\left(\mathrm{H}_{2} \mathrm{O}\right)$ & 2:1:5 & 17.75 \\
\hline N19 & Choline chloride $(\mathrm{ChCl})$-citric acid $(\mathrm{CA})$ & $1: 1$ & - \\
\hline N20 & 1,2-Propanediol (PD)-choline chloride $(\mathrm{ChCl})$-water $\left(\mathrm{H}_{2} \mathrm{O}\right)$ & 1:1:1 & 7.71 \\
\hline
\end{tabular}

Table 7. Experimental plan for the isolation of polyphenolic antioxidants from wild thyme.

\begin{tabular}{|c|c|c|c|}
\hline \multicolumn{4}{|c|}{ I Step-Screening of the Extraction Solvent } \\
\hline Approach & Constant Parameters & Factors & Responses * \\
\hline OFAT $^{1}$ & $\begin{array}{l}\text { Sample to solvent ratio: } 1: 2 \\
\text { m/mTemperature: } 50{ }^{\circ} \mathrm{C} \\
\text { Extraction time: } 60 \mathrm{~min} \\
\text { Stirring speed: } 700 \mathrm{rpm} \\
\text { Water content: } 20 \%\end{array}$ & NADES: N1-N20 & $\begin{array}{c}\mathrm{TP}^{2} \\
\mathrm{DPPH}^{3}\end{array}$ \\
\hline \multicolumn{4}{|c|}{ II Step-Preliminary Study } \\
\hline $2^{5-1}$ fractional factorial design & Stirring speed: 700 rpm & $\begin{array}{c}\text { Temperature: } 50 \text { and } 60{ }^{\circ} \mathrm{C} \\
\text { Extraction time: } 60 \text { and } 120 \mathrm{~min} \\
\text { Sample to solvent ratio: } 1: 10 \text { and } 1: 20 \mathrm{~m} / \mathrm{m} \\
\text { NADES: N15 and N16 } \\
\text { Water content: } 20 \text { and } 25 \%\end{array}$ & $\begin{array}{c}\mathrm{TP} \\
\mathrm{DPPH}\end{array}$ \\
\hline \multicolumn{4}{|c|}{ III Step-Optimization } \\
\hline RSM & $\begin{array}{c}\text { NADES: N16 } \\
\text { Water content: } 20 \% \\
\text { Stirring speed: } 700 \mathrm{rpm}\end{array}$ & $\begin{array}{c}\text { Temperature: } 40,55 \text { and } 70{ }^{\circ} \mathrm{C} \\
\text { Extraction time: } 60,120 \text { and } 180 \mathrm{~min} \\
\text { Sample to solvent ratio: } 1: 10,1: 20 \text { and } 1: 30 \mathrm{~m} / \mathrm{m}\end{array}$ & $\begin{array}{c}\text { TP } \\
\text { TF }^{4} \\
\text { DPPH } \\
\text { FRAP }^{5} \\
\text { ABTS }^{6}\end{array}$ \\
\hline
\end{tabular}

${ }^{*}$ maximized, ${ }^{1}$ One-factor-at-a-time, ${ }^{2}$ total phenol content, ${ }^{3}$ antioxidant activity toward DPPH radicals, ${ }^{4}$ total flavonoids content, ${ }^{5}$ reducing activity towards $\mathrm{Fe}^{3+}$ ions, ${ }^{6}$ antioxidant activity towards ABTS+ radicals.

Since N15 and N16 were the solvents that provided the highest total phenol content and antioxidant activity, they were selected as categorical variables in the preliminary study. Fractional $2^{5-1}$ factorial was used for that purpose, with a total of 16 experimental runs. Numerical factors at two levels were temperature $\left(50\right.$ and $\left.60{ }^{\circ} \mathrm{C}\right)$, extraction time $(60$ and $120 \mathrm{~min})$, sample to solvent ratio $(1: 10$ and $1: 20 \mathrm{~m} / \mathrm{m})$ and water content (20 and 25\%), while TP and DPPH were target responses. In order to determine the impact of NADES parameters on target responses, the linear model given by Equation (1) was used.

$$
Y=\beta_{0}+\sum_{i=1}^{5} \beta_{i} X_{i}+\sum_{i=1}^{4} \sum_{j=i+1}^{5} \beta_{i j} X_{i} X_{j}
$$


$Y$ represents the response variable, $\beta_{0}$ the intercept, $\beta_{\mathrm{i}}$ the linear regression coefficient, $\beta_{i j}$ the regression coefficients for cross-product terms and $X_{i}$ and $X_{j}$ the independent variables affecting the response.

After screening, three of the five most influential parameters were selected, which were further used in face-centered central composite experimental design (CCD) with response surface methodology (RSM). The impact of temperature $\left(40,55\right.$ and $\left.70{ }^{\circ} \mathrm{C}\right)$, extraction time $(60,120$ and $180 \mathrm{~min})$, and sample to solvent ratio $(1: 10,1: 20$ and $1: 30 \mathrm{~m} / \mathrm{m})$ were used as independent variables. Optimal extraction conditions were determined considering TP, as well as antioxidant activity parameters obtained by DPPH, ABTS and FRAP assays, while selection of optimal conditions were based on desirability function $(D)$ [43]. Results were fitted to a second-order polynomial model (Equation (2)).

$$
Y=\beta_{0}+\sum_{i=1}^{3} \beta_{i} X_{i}+\sum_{i=1}^{3} \beta_{i i} X_{i}^{2}+\sum_{i=1}^{2} \sum_{j=i+1}^{3} \beta_{i j} X_{i} X_{j}
$$

$Y$ represents the response variable, $X_{i}$ and $X_{j}$ are the independent variables affecting the response, and $\beta_{0}, \beta_{\mathrm{i}}, \beta_{\mathrm{ii}}$, and $\beta_{\mathrm{ij}}$ are the regression coefficients for intercept, linear, quadratic and cross-product terms.

\subsection{Polyphenol Analysis}

\subsubsection{Total Phenols Content}

For the determination of TP in extracts, the Folin-Ciocalteu assay was used [44]. Using a spectrophotometer (Jenway, model 6300, Staffordshire, UK), absorbances were recorded at $750 \mathrm{~nm}$, and all experiments were performed in triplicate. Mean values of the total phenols of obtained extracts were expressed as $\mathrm{mg}$ of gallic acid equivalents (GAE) per $\mathrm{g}$ of sample dry weight.

\subsubsection{Total Flavonoids Content}

Determination of TF was done using an aluminum chloride colorimetric assay [45]. Catechin was used as the standard for the preparation of the calibration curve, and absorbances were measured at $510 \mathrm{~nm}$. Results were expressed as $\mathrm{mg}$ of catechin equivalents (CE) per g DW.

\subsubsection{HPLC Analysis of Major Polyphenols}

For identification and quantification of individual phenolic compounds, the HPLC method, previously published by Mišan et al. [46], was done on an Agilent 1200 series device with a diode array detector (DAD). HPLC analysis was performed on a liquid chromatograph (Agilent 1200 series, Agilent, Santa Clara, CA, USA), equipped with a diode array detector (DAD) and Eclipse XDB-C18, $1.8 \mu \mathrm{m}, 4.6 \times 50 \mathrm{~mm}$ column. Solvents A (methanol) and B $(1 \%$ formic acid in water $(v / v))$ were used as mobile phases, with a flow rate of $1 \mathrm{~mL} / \mathrm{min}$. A solvent gradient was performed by varying the proportion of solvent $A$ to solvent $B$ as follows: at start $10 \% \mathrm{~A} ; 0-10 \mathrm{~min}, 10-25 \% \mathrm{~A} ; 10-20 \mathrm{~min}, 25-60 \%$ A; $20-30 \mathrm{~min}, 60-70 \% \mathrm{~A}$. The column temperature was set at $30^{\circ} \mathrm{C}$, while the injection volume was $5 \mu \mathrm{L}$. Optimized T. serpyllum extract was properly diluted with a mixture of mobile phases (A:B=10:90\%; v/v), filtered through a syringe filter (RC; $0.45 \mu \mathrm{m}$ ) and injected automatically into the HPLC system using an autosampler. Furthermore, detection was carried out at $280 \mathrm{~nm}$. According to the obtained surface area of the peaks, depending on the concentration standard, the calibration curve for each standard was constructed. Quantification was based on external standards calibration. The linearity range and limit of quantification (LoQ) for each compound were: gallic acid $(0.060-17.0 \mu \mathrm{g} / \mathrm{mL} ; \mathrm{LoQ}=0.060 \mu \mathrm{g} / \mathrm{mL})$, caffeic acid $(0.010-17.0 \mu \mathrm{g} / \mathrm{mL}$; $\mathrm{LoQ}=0.211 \mu \mathrm{g} / \mathrm{mL})$, epicatechin $(0.250-50.0 \mu \mathrm{g} / \mathrm{mL} ; \mathrm{LoQ}=0.250 \mu \mathrm{g} / \mathrm{mL})$, rosmarinic acid $(0.010-20.0 \mu \mathrm{g} / \mathrm{mL} ; \mathrm{LoQ}=0.074 \mu \mathrm{g} / \mathrm{mL})$, luteolin $(0.003-7.2 \mu \mathrm{g} / \mathrm{mL} ; \mathrm{LoQ}=0.087 \mu \mathrm{g} / \mathrm{mL})$ and quercetin $(0.050-20.0 \mu \mathrm{g} / \mathrm{mL} ; \mathrm{LoQ}=0.131 \mu \mathrm{g} / \mathrm{mL})$. Taking into account the obtained equation of linear concentration dependence, spectra, retention time and peak area, the 
concentrations of particular polyphenolic compounds in the tested samples were calculated, and the results were expressed as $\mathrm{mg}$ of compound per $100 \mathrm{~g}$ of sample.

\subsection{In Vitro Antioxidant Activity}

\subsubsection{Scavenging Capacity toward DPPH Radicals}

Antioxidant activity towards DPPH radicals was determined by a spectrophotometric method [47]. First, $100 \mu \mathrm{L}$ of examined extract solutions in series of different concentrations were prepared and then added to $2900 \mu \mathrm{L}$ of DPPH methanolic solution $(26 \mathrm{mg} / \mathrm{L})$. After $1 \mathrm{~h}$, absorbances were recorded at a wavelength of $517 \mathrm{~nm}$. All experiments were performed in triplicate, and the mean values of the antioxidant potential were presented as $\mathrm{mg}$ of Trolox equivalents (TE) per g DW.

\subsubsection{Reducing Capacity of $\mathrm{Fe}^{3+}$ Ions}

The reducing power of extracts was determined by the FRAP assay [48]. First, the FRAP reagent was prepared by mixing $10 \mathrm{mmol} / \mathrm{L} \mathrm{TPTZ} \mathrm{in} 40 \mathrm{mmol} / \mathrm{L} \mathrm{HCl}, 20 \mathrm{mmol} / \mathrm{L}$ $\mathrm{FeCl}_{3}$, and acetate buffer, $\mathrm{pH} 3.6$, in a ratio of 1:1:10, respectively. One hundred microliters of examined extract solutions in series of different concentrations were prepared, and $2900 \mu \mathrm{L}$ of FRAP reagent was added. After $10 \mathrm{~min}$ in the dark at $37^{\circ} \mathrm{C}$, the absorbances were recorded at a wavelength of $593 \mathrm{~nm}$. All samples were made in triplicate, and mean values of reducing power were presented as $\mathrm{mg}$ of $\mathrm{Fe}^{2+}$ per $\mathrm{g} \mathrm{DW}$.

\subsubsection{Scavenging Capacity towards $\mathrm{ABTS}^{+}$Radicals}

For the determination of antioxidant activity of Thymus extracts, ABTS assay was used as well [49]. ABTS stock solution was prepared from a mixture $(1: 1, v / v)$ of $2.45 \mathrm{mM}$ potassium persulfate aqueous solution and $7 \mathrm{mmol}$ ABTS (2,2'-azino-bis-(3-ethylbenzothiazoline6-sulfonic acid) diammonium salt) aqueous solution and left in the dark at room temperature for $16 \mathrm{~h}$. A stock solution was diluted using acetate buffer ( $\mathrm{pH} \mathrm{3.6)} \mathrm{to} \mathrm{an} \mathrm{absorbance}$ of $0.70( \pm 0.02)$ at wavelength of $734 \mathrm{~nm}$. One hundred microliters of examined extract solutions in series of different concentrations were prepared and mixed with $2900 \mu \mathrm{L}$ of ABTS reagent, after which they were stored in the dark at room temperature for $5 \mathrm{~h}$. All samples were made in triplicate, and mean values of antioxidant activity were presented as mg of Trolox equivalents (TE) per g DW.

\subsection{Nuclear Magnetic Resonance}

NMR spectroscopy was performed to obtain $1 \mathrm{D}$ and $2 \mathrm{D}$ spectra $\left({ }^{1} \mathrm{H}-\mathrm{NMR}\right.$ and ${ }^{1} \mathrm{H}-$ ${ }^{1} \mathrm{H}$ NOESY) on a Bruker Avance III 400 spectrometer (Bruker, Billerica, MA, USA) at an operating frequency of $400.13 \mathrm{MHz}$ according to the Meneses et al. [50] method. The NADES sample that was determined to be the best for polyphenol recovery (N16) was prepared in a $5 \mathrm{~mm}$ NMR tube. For the sample with NADES, $350 \mu \mathrm{L}$ of NADES and $200 \mu \mathrm{L}$ of DMSO- $d_{6}$, and for pure components, approximately $5 \mathrm{mg}$ of compound was added in the NMR tube and $500 \mu \mathrm{L}$ of DMSO- $d_{6}$. Chemical shifts were referenced to $\mathrm{Me}_{4} \mathrm{Si}$ ( $\delta$ in ppm) and the data analysis was performed with MestReNova software (Bruker, Billerica, MA, USA) (11.0.4-18998).

\subsection{Statistical Analysis}

All experiments were performed in triplicate, and the results were expressed as the mean \pm standard deviation (SD). All data from the screening of extraction solvent were analyzed by a one-factor-at-a-time (OFAT) approach using analysis of variance (ANOVA) with Tukey's multiple comparison test at $p<0.05$. Statistica 10.0 (StatSoft, Inc., Tulsa, OK, USA). Preliminary and optimization studies were analyzed by the Design of Experiments (DoE) using the aforementioned experimental designs. For multiple linear regression analysis, Design-Expert v.11 software (Stat-Ease, Minneapolis, MN, USA) was used. The goodness of fit was determined by ANOVA, while model adequacy was evaluated by the coefficient of determination $\left(R^{2}\right)$, coefficient of variance $(\mathrm{CV})$ and $p$-values for the model 
and lack of fit. In order to verify the obtained empirical models, validation was performed by using the extracts prepared under optimized NADES conditions.

\section{Conclusions}

Wild thyme herbal dust has been efficiently utilized as a raw material for the recovery of polyphenolic antioxidants using NADES extraction. A three-step optimization approach was applied in order to maximize polyphenol content (TP and TF) and improve antioxidant activity determined by DPPH, FRAP and ABTS assays. Screening of the extraction solvent was initially performed by applying the 20 different NADES systems, while all other extraction parameters were held constant. L-proline-based solvents (N15 and N16) provided the highest TP and DPPH, and they were selected for further experiments. Preliminary experiments organized via $2^{5-1}$ fractional factorial design provided information about the most influential NADES extraction parameters and their experimental domain, which should be set in further steps. Finally, RSM with three factors (temperature, extraction time and $\mathrm{L} / \mathrm{S}$ ratio) was applied for influence analysis and process optimization. Temperature and $\mathrm{L} / \mathrm{S}$ ratio were the most impactful extraction parameters affecting polyphenol content and antioxidant activity. Multi-response optimization suggested a temperature of $65^{\circ} \mathrm{C}$, time of extraction of $180 \mathrm{~min}$ and L/S ratio of $28 \mathrm{~g}$ NADES/g DW were optimal set of extraction parameters. Experimental validation confirmed good agreement between predicted and experimentally observed data and NMR analysis suggested that interactions occurred probably in -OH and - $\mathrm{NH}$ groups from glycerol and L-proline in the most suitable NADES for polyphenol recovery (N16; Pro-Gly- $\mathrm{H}_{2} \mathrm{O} ; 1: 2: 1$ ). A literature comparison suggested that NADES extraction provides a tremendous upgrade in polyphenol content and antioxidant activity of wild thyme compared to emerging extraction techniques, such as UAE and PLE. Therefore, T. serpyllum herbal dust was valorized as a good underutilized sample for polyphenol recovery, and further research should be aimed toward the incorporation of wild thyme extracts obtained by NADES extraction in functional beverages.

Supplementary Materials: The following supporting information can be downloaded, Figure S1. Influence of NADES extraction factors on (a) TP and (b) DPPH obtained in preliminary experiments; Table S1. Significance of linear, cross product and quadratic terms on TP, TF, DPPH, FRAP and ABTS; Figure S2. The effect of NADES extraction parameters (temperature, extraction time and L/S ratio) on antioxidant activity determined by (a) DPPH, (b) FRAP and (c) ABTS assays.

Author Contributions: Conceptualization, N.T. and B.P.; methodology, B.P., N.T., F.S., A.S. and A.M. (Anamarija Mandić); software, B.P. and F.S.; validation, B.P. and A.C.K.; formal analysis, B.P., F.S., Ž.M., A.S., M.P. and A.C.K.; investigation, N.T., B.P. and Ž.M.; resources, A.M. (Aleksandra Mišan), A.R.C.D. and B.P.; data curation, B.P., Ž.M. and N.T.; writing—original draft preparation, B.P.; writing—review and editing, M.P., F.S., A.R.C.D., N.T., Ž.M. and A.M. (Anamarija Mandić); visualization, B.P; supervision, A.M. (Akelsandra Mišan), A.R.C.D. and B.P.; project administration, B.P. and A.M. (Akelsandra Mišan); funding acquisition, A.R.C.D., B.P. and A.M. (Akelsandra Mišan). All authors have read and agreed to the published version of the manuscript.

Funding: This research was supported by the Science Fund of the Republic of Serbia, 6060592, Natural Deep Eutectic Solvents for Green Agri-Food Solutions-DEStiny and 7750168, Novel extracts and bioactive compounds from under-utilized resources for high-value applications-BioUtilize. This project received funding from the European Union's Horizon 2020-European Research Council (ERC)-under grant agreement No ERC-2016-CoG 725034. This work was supported by the Associate Laboratory for Green Chemistry (LAQV), which is financed by national funds from FCT/MCTES (UIDB/50006/2020).

Institutional Review Board Statement: Not applicable.

Informed Consent Statement: Not applicable.

Data Availability Statement: Data are contained within the article or Supplementary Material. 
Conflicts of Interest: The authors declare no conflict of interest. The funders had no role in the design of the study; in the collection, analyses, or interpretation of data; in the writing of the manuscript, or in the decision to publish the results.

Sample Availability: Samples of the compounds are not available from the authors.

\section{References}

1. Jarić, S.; Mitrović, M.; Pavlović, P. Review of ethnobotanical, phytochemical, and pharmacological study of Thymus serpyllum L. Evid.-based Complement. Altern. Med. 2015, 2015, 101978. [CrossRef] [PubMed]

2. Boros, B.; Jakabová, S.; Dörnyei, Á.; Horváth, G.; Pluhár, Z.; Kilár, F.; Felinger, A. Determination of polyphenolic compounds by liquid chromatography-mass spectrometry in Thymus species. J. Chromatogr. A 2010, 1217, 7972-7980. [CrossRef] [PubMed]

3. Chemat, F.; Vian, M.A.; Cravotto, G. Green extraction of natural products: Concept and principles. Int. J. Mol. Sci. 2012, 13, 8615-8627. [CrossRef]

4. Ramić, M.; Vidović, S.; Zeković, Z.; Vladić, J.; Cvejin, A.; Pavlić, B. Modeling and optimization of ultrasound-assisted extraction of polyphenolic compounds from Aronia melanocarpa by-products from filter-tea factory. Ultrason. Sonochem. 2015, 23, 360-368. [CrossRef]

5. Naffati, A.; Vladić, J.; Pavlić, B.; Radosavljević, R.; Gavarić, A.; Vidović, S. Recycling of filter tea industry by-products: Application of subcritical water extraction for recovery of bioactive compounds from A. uva-ursi herbal dust. J. Supercrit. Fluids 2017, 121, 1-9. [CrossRef]

6. Rombaut, N.; Tixier, A.S.; Bily, A.; Chemat, F. Green extraction processes of natural products as tools for biorefinery. Biofuel. Bioprod. Biorefin. 2014, 8, 530-544. [CrossRef]

7. Mrkonjić, Ž.; Rakić, D.; Olgun, E.O.; Canli, O.; Kaplan, M.; Teslić, N.; Zeković, Z.; Pavlić, B. Optimization of antioxidants recovery from wild thyme (Thymus serpyllum L.) by ultrasound-assisted extraction: Multi-response approach. J. Appl. Res. Med. Aromat. Plants 2021, 24, 100333. [CrossRef]

8. Mrkonjić, Ž.; Rakić, D.; Kaplan, M.; Teslić, N.; Zeković, Z.; Pavlić, B. Pressurized-liquid extraction as an efficient method for valorization of Thymus serpyllum herbal dust towards sustainable production of antioxidants. Molecules 2021, 26, 2548. [CrossRef]

9. Tobiszewski, M.; Namieśnik, J.; Pena-Pereira, F. Environmental risk-based ranking of solvents using the combination of a multimedia model and multi-criteria decision analysis. Green Chem. 2017, 19, 1034-1042. [CrossRef]

10. Bakirtzi, C.; Triantafyllidou, K.; Makris, D.P. Novel lactic acid-based natural deep eutectic solvents: Efficiency in the ultrasoundassisted extraction of antioxidant polyphenols from common native Greek medicinal plants. J. Appl. Res. Med. Aromat. Plants 2016, 3, 120-127. [CrossRef]

11. Benvenutti, L.; Zielinski, A.A.F.; Ferreira, S.R.S. Which is the best food emerging solvent: IL, DES or NADES? Trends Food Sci. Technol. 2019, 90, 133-146. [CrossRef]

12. Mišan, A.; Nađpal, J.; Stupar, A.; Pojić, M.; Mandić, A.; Verpoorte, R.; Choi, Y.H. The perspectives of natural deep eutectic solvents in agri-food sector. Crit. Rev. Food Sci. Nutr. 2019, 60, 2564-2592. [CrossRef] [PubMed]

13. Chanioti, S.; Tzia, C. Extraction of phenolic compounds from olive pomace by using natural deep eutectic solvents and innovative extraction techniques. Innov. Food Sci. Emerg. Technol. 2018, 48, 228-239. [CrossRef]

14. Ivanović, M.; Alañón, M.E.; Arráez-Román, D.; Segura-Carretero, A. Enhanced and green extraction of bioactive compounds from Lippia citriodora by tailor-made natural deep eutectic solvents. Food Res. Int. 2018, 111, 67-76. [CrossRef]

15. Miličević, N.; Panić, M.; Valinger, D.; Cvjetko Bubalo, M.; Benković, M.; Jurina, T.; Gajdoš Kljusurić, J.; Radojčić Redovniković, I.; Jurinjak Tušek, A. Development of continuously operated aqueous two-phase microextraction process using natural deep eutectic solvents. Sep. Purif. Technol. 2020, 244, 116746. [CrossRef]

16. Popovic, B.M.; Micic, N.; Potkonjak, A.; Blagojevic, B.; Pavlovic, K.; Milanov, D.; Juric, T. Novel extraction of polyphenols from sour cherry pomace using natural deep eutectic solvents-Ultrafast microwave-assisted NADES preparation and extraction. Food Chem. 2022, 366, 130562. [CrossRef]

17. da Silva, D.T.; Smaniotto, F.A.; Costa, I.F.; Baranzelli, J.; Muller, A.; Somacal, S.; Monteiro, C.S.A.; Vizzotto, M.; Rodrigues, E.; Barcia, M.T.; et al. Natural deep eutectic solvent (NADES): A strategy to improve the bioavailability of blueberry phenolic compounds in a ready-to-use extract. Food Chem. 2021, 364, 130370. [CrossRef]

18. Choi, Y.H.; van Spronsen, J.; Dai, Y.; Verberne, M.; Hollmann, F.; Arends, I.W.C.E.; Witkamp, G.J.; Verpoorte, R. Are Natural Deep Eutectic Solvents the Missing Link in Understanding Cellular Metabolism and Physiology? Plant Physiol. 2011, 156, 1701-1705. [CrossRef]

19. Shikov, A.N.; Narkevich, I.A.; Flisyuk, E.V.; Luzhanin, V.G.; Pozharitskaya, O.N. Medicinal plants from the 14th edition of the Russian Pharmacopoeia, recent updates. J. Ethnopharmacol. 2021, 268, 113685. [CrossRef]

20. Fernández, M.d.l.Á.; Boiteux, J.; Espino, M.; Gomez, F.J.V.; Silva, M.F. Natural deep eutectic solvents-mediated extractions: The way forward for sustainable analytical developments. Anal. Chim. Acta 2018, 1038, 1-10. [CrossRef]

21. Hagerman, A.E.; Butler, L.G. The specificity of proanthocyanidin-protein interactions. J. Biol. Chem. 1981, 256, 4494-4497. [CrossRef]

22. Nam, M.W.; Zhao, J.; Lee, M.S.; Jeong, J.H.; Lee, J. Enhanced extraction of bioactive natural products using tailor-made deep eutectic solvents: Application to flavonoid extraction from Flos sophorae. Green Chem. 2015, 17, 1718-1727. [CrossRef] 
23. Mansinhos, I.; Gonçalves, S.; Rodríguez-Solana, R.; Ordóñez-Díaz, J.L.; Moreno-Rojas, J.M.; Romano, A. Ultrasonic-Assisted Extraction and Natural Deep Eutectic Solvents Combination: A Green Strategy to Improve the Recovery of Phenolic Compounds from Lavandula pedunculata subsp. lusitanica (Chaytor) Franco. Antioxidants 2021, 10, 582. [CrossRef]

24. Huang, Y.; Yang, J.; Zhao, Y.; Yu, L.; He, Y.; Wan, H.; Li, C. Screening, Optimization, and Bioavailability Research of Natural Deep Eutectic Solvent Extracts from Radix Pueraria. Molecules 2021, 26, 729. [CrossRef] [PubMed]

25. Dai, Y.; Witkamp, G.J.; Verpoorte, R.; Choi, Y.H. Tailoring properties of natural deep eutectic solvents with water to facilitate their applications. Food Chem. 2015, 187, 14-19. [CrossRef]

26. Faggian, M.; Sut, S.; Perissutti, B.; Baldan, V.; Grabnar, I.; Dall'Acqua, S. Natural Deep Eutectic Solvents (NADES) as a Tool for Bioavailability Improvement: Pharmacokinetics of Rutin Dissolved in Proline/Glycine after Oral Administration in Rats: Possible Application in Nutraceuticals. Molecules 2016, 21, 1531. [CrossRef]

27. Guo, N.; Ping-Kou; Jiang, Y.W.; Wang, L.T.; Niu, L.J.; Liu, Z.M.; Fu, Y.J. Natural deep eutectic solvents couple with integrative extraction technique as an effective approach for mulberry anthocyanin extraction. Food Chem. 2019, 296, 78-85. [CrossRef]

28. Shikov, A.N.; Kosman, V.M.; Flissyuk, E.V.; Smekhova, I.E.; Elameen, A.; Pozharitskaya, O.N. Natural Deep Eutectic Solvents for the Extraction of Phenyletanes and Phenylpropanoids of Rhodiola rosea L. Molecules 2020, 25, 1826. [CrossRef]

29. Doldolova, K.; Bener, M.; Lalikoğlu, M.; Aşçı, Y.S.; Arat, R.; Apak, R. Optimization and modeling of microwave-assisted extraction of curcumin and antioxidant compounds from turmeric by using natural deep eutectic solvents. Food Chem. 2021, $353,129337$. [CrossRef]

30. Ivanović, M.; Albreht, A.; Krajnc, P.; Vovk, I.; Razboršek, M.I. Sustainable ultrasound-assisted extraction of valuable phenolics from inflorescences of Helichrysum arenarium L. using natural deep eutectic solvents. Ind. Crops Prod. 2021, 160, 113102. [CrossRef]

31. Myers, R.H.; Montgomery, D.C.; Anderson-Cook, C.M. Response Surface Methodology: Process and Product Optimization Using Designed Experiments, 4th ed.; Wiley \& Sons Ltd.: New York, NY, USA, 2016; p. 894.

32. Bosiljkov, T.; Dujmić, F.; Cvjetko Bubalo, M.; Hribar, J.; Vidrih, R.; Brnčić, M.; Zlatic, E.; Radojčić Redovniković, I.; Jokić, S. Natural deep eutectic solvents and ultrasound-assisted extraction: Green approaches for extraction of wine lees anthocyanins. Food Bioprod. Process. 2017, 102, 195-203. [CrossRef]

33. Alañón, M.E.; Ivanović, M.; Pimentel-Mora, S.; Borrás-Linares, I.; Arráez-Román, D.; Segura-Carretero, A. A novel sustainable approach for the extraction of value-added compounds from Hibiscus sabdariffa L. calyces by natural deep eutectic solvents. Food Res. Int. 2020, 137, 109646. [CrossRef] [PubMed]

34. Jovanović, A.A.; Djordjević, V.B.; Petrović, P.M.; Pljevljakušić, D.S.; Zdunić, G.M.; Šavikin, K.P.; Bugarski, B.M. The influence of different extraction conditions on polyphenol content, antioxidant and antimicrobial activities of wild thyme. J. Appl. Res. Med. Aromat. Plants 2021, 25, 100328. [CrossRef]

35. Jovanović, A.A.; Đorđević, V.B.; Zdunić, G.M.; Pljevljakušić, D.S.; Šavikin, K.P.; Gođevac, D.M.; Bugarski, B.M. Optimization of the extraction process of polyphenols from Thymus serpyllum L. herb using maceration, heat- and ultrasound-assisted techniques. Sep. Purif. Technol. 2017, 179, 369-380. [CrossRef]

36. Bi, W.; Tian, M.; Row, K.H. Evaluation of alcohol-based deep eutectic solvent in extraction and determination of flavonoids with response surface methodology optimization. J. Chromatogr. A 2013, 1285, 22-30. [CrossRef]

37. Katsampa, P.; Valsamedou, E.; Grigorakis, S.; Makris, D.P. A green ultrasound-assisted extraction process for the recovery of antioxidant polyphenols and pigments from onion solid wastes using Box-Behnken experimental design and kinetics. Ind. Crops Prod. 2015, 77, 535-543. [CrossRef]

38. Obluchinskaya, E.D.; Pozharitskaya, O.N.; Zakharova, L.V.; Daurtseva, A.V.; Flisyuk, E.V.; Shikov, A.N. Efficacy of Natural Deep Eutectic Solvents for Extraction of Hydrophilic and Lipophilic Compounds from Fucus vesiculosus. Molecules 2021, $26,4198$. [CrossRef]

39. Teslic, N.; Santos, F.; Oliveira, F.; Stupar, A.; Pojić, M.; Mandić, A.; Pavlić, B.; Cvetanović Kljakić, A.; Duarte, A.R.C.; Paiva, A.; et al. Simultaneous Hydrolysis of Ellagitannins and Extraction of Ellagic Acid from Defatted Raspberry Seeds Using Natural Deep Eutectic Solvents (NADES). Antioxidants 2022, 11, 254. [CrossRef]

40. Craveiro, R.; Aroso, I.; Flammia, V.; Carvalho, T.; Viciosa, M.T.; Dionísio, M.; Barreiros, S.; Reis, R.L.; Duarte, A.R.C.; Paiva, A. Properties and thermal behavior of natural deep eutectic solvents. J. Mol. Liq. 2016, 215, 534-540. [CrossRef]

41. Manuela, P.; Drakula, S.; Cravotto, G.; Verpoorte, R.; Hruškar, M.; Radojčić Redovniković, I.; Radošević, K. Biological activity and sensory evaluation of cocoa by-products NADES extracts used in food fortification. Innov. Food Sci. Emerg. Technol. 2020, 66, 102514. [CrossRef]

42. Dai, Y.; van Spronsen, J.; Witkamp, G.J.; Verpoorte, R.; Choi, Y.H. Natural deep eutectic solvents as new potential media for green technology. Anal. Chim. Acta 2013, 766, 61-68. [CrossRef]

43. Derringer, G.; Suich, R. Simultaneous Optimization of Several Response Variables. J. Qual. Technol. 1980, 12, 214-219. [CrossRef]

44. Singleton, V.L.; Rossi, J.A.J. Colorimetry of Total Phenolics with Phosphomolybdic-Phosphotungstic Acid Reagents. Am. J. Enol. Vitic. 1965, 16, 144-158. [CrossRef]

45. Harborne, J.B. Methods of Plant Analysis; Springer: Dordrecht, The Netherlands, 1984.

46. Mišan, A.Č.; Mimica-Dukić, N.M.; Mandić, A.I.; Sakač, M.B.; Milovanović, I.L.; Sedej, I.J. Development of a Rapid Resolution HPLC method for the separation and determination of 17 phenolic compounds in crude plant extracts. Cent. Eur. J. Chem. 2011, 9 , 133-142. [CrossRef] 
47. Brand-Williams, W.; Cuvelier, M.E.; Berset, C. Use of a free radical method to evaluate antioxidant activity. LWT 1995, 28, 25-30. [CrossRef]

48. Benzie, I.F.F.; Strain, J.J. The Ferric Reducing Ability of Plasma (FRAP) as a Measure of "Antioxidant Power": The FRAP Assay. Anal. Biochem. 1996, 239, 70-76. [CrossRef] [PubMed]

49. Re, R.; Pellegrini, N.; Proteggente, A.; Pannala, A.; Yang, M.; Rice-Evans, C. Antioxidant activity applying an improved ABTS radical cation decolorization assay. Free Radic. Biol. Med. 1999, 26, 1231-1237. [CrossRef]

50. Meneses, L.; Santos, F.; Gameiro, A.R.; Paiva, A.; Duarte, A.R.C. Preparation of Binary and Ternary Deep Eutectic Systems. J. Vis. Exp. 2019, 152, e60326. [CrossRef] 